\title{
Gastric proton pump with two occluded K+ engineered with sodium pump-mimetic mutations
}

Kazuhiro Abe ( $\nabla$ kabe@cespi.nagoya-u.ac.jp )

Nagoya University https://orcid.org/0000-0003-2681-5921

Kenta Yamamoto

Nagoya University

Katsumasa Irie

Nagoya University

Tomohiro Nishizawa

Yokohama City University

Atsunori Oshima

Nagoya University https://orcid.org/0000-0003-1174-1368

\section{Article}

Keywords: gastric proton pump, $\mathrm{K}+$, sodium pump-mimetic mutations

Posted Date: June 9th, 2021

DOI: https://doi.org/10.21203/rs.3.rs-584680/v1

License: (c) (i) This work is licensed under a Creative Commons Attribution 4.0 International License. Read Full License

Version of Record: A version of this preprint was published at Nature Communications on September 29th, 2021. See the published version at https://doi.org/10.1038/s41467-021-26024-1. 


\title{
Gastric proton pump with two occluded $\mathrm{K}^{+}$engineered with sodium pump-mimetic mutations
}

\author{
Kazuhiro Abe, ${ }^{1,2^{*}}$ Kenta Yamamoto, ${ }^{1,2}$ Katsumasa Irie, ${ }^{3}$ Tomohiro Nishizawa, ${ }^{4}$ Atsunori Oshima ${ }^{1,2}$ \\ ${ }^{1}$ Cellular and Structural Physiology Institute, Nagoya University, 464-8601, Japan \\ ${ }^{2}$ Graduate School of Pharmaceutical Sciences, Nagoya University, 464-8601, Japan \\ ${ }^{3}$ Department of Biophysical Chemistry, Faculty of Pharmaceutical Sciences, Wakayama Medical \\ University, Wakayama, 25-1 Shichibancho, 640-8156, Japan \\ ${ }^{4}$ Graduate School of Medical Life Science, Yokohama City University, Tsurumi, Yokohama, 230-0045, \\ Japan \\ *Correspondence: Kazuhiro Abe, kabe@cespi.nagoya-u.ac.jp
}

\begin{abstract}
The gastric $\mathrm{H}^{+}, \mathrm{K}^{+}$-ATPase mediates electroneutral exchange of $1 \mathrm{H}^{+} / 1 \mathrm{~K}^{+}$per ATP hydrolysed across the membrane. Previous structural analysis of the $\mathrm{K}^{+}$-occluded E2-Pi form of $\mathrm{H}^{+}, \mathrm{K}^{+}$-ATPase showed a single bound $\mathrm{K}^{+}$at cation-binding site II, in marked contrast to the two $\mathrm{K}^{+}$occluded at sites I and II of the closelyrelated $\mathrm{Na}^{+}, \mathrm{K}^{+}$-ATPase which mediates electrogenic $3 \mathrm{Na}^{+} / 2 \mathrm{~K}^{+}$translocation across the membrane. The two pumps show significant differences in structure in and around Site I, but which are critical for blocking $\mathrm{K}^{+}$ binding in the gastric pump and contribute to binding in the sodium pump is unclear. We have a series of crystal structures and a cryo-EM structure of $\mathrm{H}^{+}, \mathrm{K}^{+}$-ATPase mutants with changes in the vicinity of site I based on the structure of the sodium pump. The number of bound $\mathrm{Rb}^{+}$, determined by its anomalous dispersion, remains one in the luminal-open E2BeF form of the Lys791Ser single mutant and Lys791Ser/Glu820Asp double mutant, mutation that could create space and may directly bind the cation. We next introduced mutations in peripheral residues Try340Asn and Glu936Val. A strong and spread-out $\mathrm{Rb}^{+}$anomalous density observed in the quadruple mutant suggests that a certain population ATPases has two $\mathrm{Rb}^{+}$bound. We then added gate-closing mutation Try799Trp and determined its cryo-EM structure in the occluded E2-AlF form. This quintuple mutant unambiguously has two separate densities at the cationbinding site. The step-wise construction of the $\mathrm{K}^{+}$binding site offers new insight into how it is blocked in the one pump and constituted in the other.

\section{Introduction}

P-type ATPases are a family of membrane proteins that couple the active transport of their specific substances to ATP hydrolysis (1). The reaction mechanisms of P2-type cation pumps, including $\mathrm{Na}^{+}, \mathrm{K}^{+}-$ ATPase (NKA), sarcoplasmic reticulum $\mathrm{Ca}^{2+}$-ATPase (SERCA) and gastric proton pump $\mathrm{H}^{+}, \mathrm{K}^{+}$-ATPase (HKA), have been well studied at the molecular level (2-4). The architecture of the catalytic subunits of the P2 family is highly conserved and consists of ten transmembrane (TM) helices in which cation-binding sites are located, and three cytoplasmic domains (actuator A-, phosphorylation P- and nucleotide-binding $\mathrm{N}$-domains) required for ATP hydrolysis. The active transport of cations by P2-type ATPases is accomplished by cyclical conformational changes of the whole enzyme (abbreviated as "E") and is generally described using E1/E2 nomenclature based on the Post-Albers scheme for NKA (Fig. 1A) (5-7). During the transport cycle, a conserved aspartate in the DKTG sequence is reversibly auto-phosphorylated to form phosphoenzyme intermediates (EPs), a hallmark of P-type ATPases (8). Coupled ATP hydrolysis and ion transport is achieved by large structural changes throughout the enzyme and these have been well studied at the molecular level through numerous crystal structures and functional analyses (9-11).
\end{abstract}


Among the P2-type cation transporting ATPases, HKA and NKA possess remarkable similarities, including their reaction mechanisms, subunit composition, and high sequence identity of the catalytic $\alpha$ subunit (approximately 65\%, Fig. 1C). However, their cation selectivity and transport stoichiometry need to be very specific in order to achieve their respective physiological roles. HKA acidifies gastric juice down to $\mathrm{pH} 1$, which corresponds to a more than one million-fold $\mathrm{H}^{+}$gradient, one of the highest gradients known in mammalian tissue $(12,13)$. Therefore, because of the limited free energy available from ATP hydrolysis, the stoichiometry of transported cations needs to be strictly $1 \mathrm{H}^{+} / 1 \mathrm{~K}^{+}$per ATP to satisfy the thermodynamic requirement (14-16). On the other hand, NKA exchanges three $\mathrm{Na}^{+}$and two $\mathrm{K}^{+}$per ATP hydrolysis, to generate the approximately tenfold $\mathrm{Na}^{+}$gradient essential for the secondary transport, action potentials in excitable cells (17) and other important cellular functions. Besides the strict discrimination of $\mathrm{H}^{+}$and $\mathrm{Na}^{+}$ in the E1 state, a notable difference is the number of counter-transporting $\mathrm{K}^{+}$per cycle.

Crystal structures of NKA (18) and HKA (16) in the $\mathrm{K}^{+}$-occluded state define the structural basis of bound $\mathrm{K}^{+}$at the cation-binding site. The cation-binding site is formed in the middle of the membrane domain, surrounded by TM4, TM5, TM6 and TM8 in both HKA and NKA (Fig.1). In the cation-binding site of HKA in the $\mathrm{K}^{+}$-occluded E2-P $\mathrm{P}_{\mathrm{i}}$ state (16), a single $\mathrm{K}^{+}$is at a position corresponding to site II in NKA (Fig. 1BC). In both $\mathrm{K}^{+}$-counter-transporting pumps, the $\mathrm{K}^{+}$ions are coordinated by oxygen atoms from main chain carboxyl and hydrophilic side chains. To elucidate the molecular basis of the different $\mathrm{K}^{+}$ stoichiometry in these two pumps, we evaluated a series of NKA-mimetic mutants of HKA with increasing substitutions. Five substitutions created a two- $\mathrm{K}^{+} \mathrm{HKA}$ mutant, which shows the importance of not only direct ion coordinating residues but also secondary supporting residues.

\section{Results and Discussion \\ Crystal structures of K791S and K791S/E820D mutants}

The first obvious difference between the cation-binding pockets of HKA and NKA is the presence of Lys791 in TM5 of HKA - this corresponds to Ser782 in NKA that directly coordinates $\mathrm{K}^{+}$at site I (Fig. 1D-I). In the E2P intermediate state, the lysine forms a salt bridge with neighboring Glu820 (Asp811 in NKA) on TM6, a side chain which likely participants in $\mathrm{H}^{+}$extrusion to the lumen of the stomach (4). Mutation Lys791Ser in HKA has serious consequences and demonstrates the importance of the state-specific salt bridge for function (19). The transport stoichiometry of the mutant is unknown due to its unaltered nonelectrogenic transport properties. We generated the NKA-mimetic single mutant Lys791Ser (KS) and a double mutant Lys791Ser/Glu820Asp (KS/ED) of HKA and determined their crystal structures. The thermal stabilities (Fig. 2, Table S1) and normalized specific ATPase activities (Fig. 2, Table S2) of these two mutants are significantly reduced compared to those of wild type (Fig. 2, Table S2), suggesting the mutations destabilize the cation-binding site. In keeping with this, these mutants failed to form suitable crystals for analysis in the presence of transition state phosphate analog aluminum fluoride $\left(\mathrm{AlF}_{4}^{-}\right.$, stabilizes a $\left(\mathrm{K}^{+}\right) \mathrm{E} 2-$ AlF state) (Table S1). Therefore, we proceeded to crystallize them in the presence of phosphate analog beryllium fluoride $\left(\mathrm{BeF}_{3}^{-}\right)$and $\mathrm{K}^{+}$-competitive acid blocker (P-CAB) BYK99, a high affinity analog of $\mathrm{SCH} 28080$ with a fixed ring structure (20), which stabilizes the molecular conformation in a luminal-open but $\mathrm{K}^{+}$-bound E2P ground state (Fig. 1A). In the crystal structure of wild type HKA in the (SCH)E2BeF state (pdb ID: 5ylv) (4), a single $\mathrm{Rb}^{+}$appears close to cation binding site II, which is in good agreement with a single $\mathrm{K}^{+}$-occluded in $\left(\mathrm{K}^{+}\right) \mathrm{E} 2-\mathrm{MgF}$ state structures $(6 \mathrm{jxh})(16)$. In the crystal structure of NKA bufalin (ouabain analog)-bound $\mathrm{E} 2 \mathrm{BeF}$ state (4res) (21), two $\mathrm{K}^{+}$are in cation-binding sites I and II as in the $\mathrm{K}^{+}$occluded form $\left(\mathrm{K}^{+}\right)_{2} \mathrm{E} 2-\mathrm{MgF}$ state (2zxe) (18). Consequently, we expected that if two $\mathrm{K}^{+}$ions (or its congener $\mathrm{Rb}^{+}$) are present in HKA with NKA-mimetic mutations, we would be able to detect them in the crystal structures and the anomalous $\mathrm{Rb}^{+}$scattering.

The Lys791Ser (KS) single mutant structure in the (BYK99)E2BeF form was analyzed at $3.4 \AA$ resolution (Table S3). However, crystals obtained with the Lys791Ser/Glu820Asp double mutant (KS/ED) showed limited diffraction, at around $4.5 \AA$ resolution. Although molecular replacement allowed for phasing of the KS/ED crystal, we did not perform further refinement due to the limited resolution. Anomalous difference Fourier maps from bound $\mathrm{Rb}^{+}$in both mutants show unambiguously a single peak at site II (Fig. $3 \mathrm{~B}, \mathrm{C})$, which indicates that the number of $\mathrm{Rb}^{+}$bound to the cation-binding site in either mutant remains the 
same as that of wild type. Simple replacement of amino acid residues that directly coordinate $\mathrm{K}^{+}$at site I of NKA could not form a second $\mathrm{K}^{+}$-binding site in HKA.

Even though we achieved a $3.4 \AA$ resolution for the KS single mutant, the electron density map cannot resolve some amino acid side chains in the cation-binding site (Fig. S1). In particular the electron densities corresponding to the side chains of Glu795 and Asn792 are barely discernible (Fig. S1, red arrowhead), most likely because the mutations disturb the hydrogen-bond network in the cation binding site, destabilizing the structure. This may be reflected in the reduced thermal stability and ATPase activity of these mutants (Fig. 2, Table S1,S2).

\section{Crystal structure of the Lys791Ser/Glu820Asp/Try340Asn triple mutant}

In both the $(\mathrm{SCH}) \mathrm{E} 2 \mathrm{BeF}$ and $\left(\mathrm{K}^{+}\right) \mathrm{E} 2-\mathrm{MgF}$ states of wild type $\mathrm{HKA}$, the rotamer conformation adopted by the side chain of Asn792 has its nitrogen pointing to site II, preventing the oxygen atom in this residue coordinating with the $\mathrm{K}^{+}$there (Fig. 1D). This is in marked contrast to the NKA structure in which the corresponding Asn783 side chain oxygen coordinates $\mathrm{K}^{+}$at both site I and site II at $3.0 \AA$ and $2.8 \AA$, respectively (Fig. 1F). Therefore, a key question in understanding the difference in the number of $\mathrm{K}^{+}$ions in HKA and NKA is to ascertain the determinants of the rotamer conformation of the conserved asparagine residue. In NKA, Asn783 forms a hydrogen-bond with the side chain oxygen of Tyr854 (3.1A) (Fig. 1F).

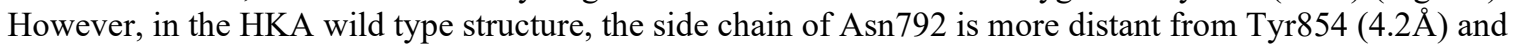
cannot form a hydrogen bond (Fig. 1D). It appears from the structures that this is caused by close TM4 residues. Here, the side chain of Tyr340 in HKA, which corresponds to Asn331 in NKA, faces Tyr863, pushing it far from Asn792. Consequently, a water is introduced in the empty space between Tyr863 and Asn792 and connects them. In fact, when HKA and NKA structures are superimposed, Tyr340 in TM4 of HKA clashes with Tyr854 in TM7 of NKA (Fig. 1H,I). Therefore, we hypothesized that an additional mutation of Tyr340Asn in HKA could change the Asn792 rotamer conformation indirectly and make the Asn792 oxygen point to the $\mathrm{K}^{+}$-binding site.

The reduced thermal stabilities of the KS and KS/ED mutants (Fig. 2, Table S1) result from the introduction of NKA-type mutations, and they evidently interfere with surrounding side chains. It is possible the instabilities may be reversed by a correcting Tyr340Asn mutation. Indeed, the triple mutant Lys791S/Glu820Asp/Tyr340Asn (KS/ED/YN) is significantly more thermally stable (Fig. 2, Table S1). Moreover, as crystal quality often correlates with the thermal stability, triple mutant KS/ED/YN crystals diffracted at an improved 3.2 $\AA$ resolution (Fig. 4A-D, Table S3). As predicted, introduction of the Tyr340Asn mutation in HKA unlocked the sterically tight conformation of Try863 in TM7 (Fig. 4A,C), and assumed the orientation of NKA (Fig. 4D). In the triple mutant, the oxygen atom of Tyr863 and the polar side chain of Asn792 are $3.2 \AA$ apart, a favorable distance for a hydrogen bond to form between the nitrogen and oxygen atoms (22), and certainly close enough to interact directly without water. The rotamer conformation of Asn792 cannot be explicitly determined in the $3.2 \AA$ resolution map, and so we used a "Nakagawa's Bees" analysis to determine the asparagine rotamer outliers in the refinement according to their temperature factors. This analysis confirms that the rotamer is of NKA-type, i.e., the side chain oxygen faces towards the $\mathrm{K}^{+}$at site II. Therefore, both the improved thermal stability and relationship of Asn792 with surrounding side chains is evidence that the structure here is indeed close to that of NKA.

However, the anomalous signal from bound $\mathrm{Rb}^{+}$shows a globular density centered at site II (Fig. 2D, Fig. 4B) and no significant density at the site I position, indicating that there is only one $\mathrm{Rb}^{+}$bound, and that is at site II as in wild type HKA. In the KS/ED/YN triple mutant, the side chains directly coordinating $\mathrm{K}^{+}$, including the conformation of Asn792, appear to be NKA-like. However, a detailed comparison of the crystal structures of HKA triple mutant $(\mathrm{KS} / \mathrm{ED} / \mathrm{YN})$ in the BYK99-bound $\mathrm{E} 2 \mathrm{BeF}$ state, and NKA wild type in the bufalin-bound E2P state suggested that an inappropriate position of Lys791Ser in HKA may be preventing an extra $\mathrm{K}^{+}$from binding at the site I position (Fig. 4D). The side chain projects to the side of site I and is not focused to a hypothetical $\mathrm{K}^{+}$here. In NKA, the $\mathrm{K}^{+}$at site I is coordinated by Ser782 at $2.6 \AA$, and its mutation significantly reduces $\mathrm{K}^{+}$-affinity (23)

It appeared to us that to correct the orientation of Lys791Ser we would need to adjust the position of neighboring Asp824 in TM6. In NKA the corresponding Asp815 does not directly coordinates $\mathrm{K}^{+}$, but forms a hydrogen bond with Ser782 and likely fixes the serine's side chain in a position suitable for $\mathrm{K}^{+}-$ 
coordination at site I (Fig. 1F). However, in the wild type and HKA triple mutant, Asp824 is facing towards the other side by forming a hydrogen bond with Glu936 in TM8 (Val927 in NKA), and therefore does not

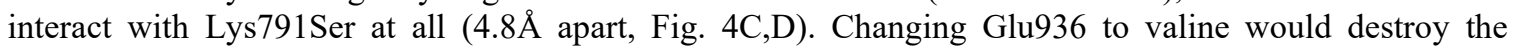
hydrogen bond and possibly reorient Asp824 and therefore Lys791Ser. Accordingly, we introduce a Glu936Val mutation within the triple mutant and determined its crystal structure and $\mathrm{Rb}^{+}$anomalous scattering.

\section{Crystal structure of the quadruple mutant}

In the structure of the quadruple mutant Lys791Ser/Glu820Asp/Tyr340Asn/Glu936Val (KS/ED/YN/EV), analyzed at $3.2 \AA$ resolution (Fig. 4E-H, Table S1), the side chain of Asp824 does indeed face Lys791Ser due to the loss of the hydrogen bond with Glu936Val in TM8, (Fig. 4E); however, the distance between Lys791Ser and Asp824 is 4.1 $\AA$, likely insufficient for the desired strong linking hydrogen bond (Fig. 4G). Consequently, the position of Lys791Ser remains different from that of Ser783 in NKA, disrupting $\mathrm{K}^{+}$binding site I (Fig. $4 \mathrm{H}$ ).

Nevertheless, the anomalous difference Fourier map from bound $\mathrm{Rb}^{+}$in the quadruple mutant shows a spread density distributed around site II and it is elongated towards site I (Fig. 4F), significantly different from the spherical density observed in the wild type (4) and other HKA mutants (Fig. 3). This elongated map is unlikely to represent a single $\mathrm{Rb}^{+}$bound at site II. To evaluate the significance of this $\mathrm{Rb}^{+}$density, we quantitatively compared the $\mathrm{Rb}^{+}$densities in each of the mutants (Fig. 5). There is a single monovalent cation is bound to the P-domain in most of P2-type ATPase crystal structures $(2,3)$, including one $\mathrm{Rb}^{+}$in HKA wild type (5ylu, ref. 4, see Fig. 3 black arrowheads), and we can conveniently use the density value at the $\mathrm{Rb}^{+}$site in this domain as a reference standard for the stoichiometry of $\mathrm{Rb}^{+}$-binding. In the single $\mathrm{KS}$ and double $\mathrm{KS} / \mathrm{ED}$ mutants, the $\mathrm{Rb}^{+}$density at the cation-binding site is weaker than that in the P-domain, reflecting an unstable cation-binding site, as discussed above. In the triple mutant, $\mathrm{Rb}^{+}$densities at the P-domain and the cation-binding sites show comparable values, as seen in the wild type, suggesting stoichiometric $\mathrm{Rb}^{+}$-binding at both sites. In marked contrast, in the quadruple mutant, the $\mathrm{Rb}^{+}$density at the cation-binding site is significantly stronger than that at the P-domain (Fig. 5), suggesting that more than one $\mathrm{Rb}^{+}$is bound to the cation-binding site. However, when we modeled two $\mathrm{Rb}^{+}$ions according to the anomalous density distribution (Fig. 4F), the two $\mathrm{Rb}^{+}$ions became very close to each other $(2.7 \AA)$, and the one on the site I side showed a very high temperature factor $(B$-factor $=170)$ after iterative refinement. Therefore, although the observed strong $\mathrm{Rb}^{+}$density in the quadruple mutant suggests the binding of more than one $\mathrm{Rb}^{+}$ion at the cation-binding site, the second $\mathrm{Rb}^{+}$is unlikely to be well coordinated at site $\mathrm{I}$, in stark contrast to the NKA, where the two $\mathrm{K}^{+}$ions are $4.1 \AA$ apart. Consequently, we conclude that the crystal structure of the HKA quadruple mutant is obtained as a mixture of one $\mathrm{Rb}^{+}$- and two $\mathrm{Rb}^{+}$-bound protein molecules in the crystal lattice.

\section{Cryo-EM structure of a two $\mathrm{K}^{+}$-occluded quintuple mutant}

All of the above crystal structures were determined in the BYK99-bound E2BeF ground state in which the luminal gate is widely open, and hence $\mathrm{Rb}^{+}$is expected to be bound, but not occluded, reflecting a low-affinity mode, in contrast to the $\mathrm{K}^{+}$-occluded E2-AlF transition form. The spread and strong $\mathrm{Rb}^{+}$density in the quadruple mutant encouraged us to crystallize $\mathrm{a} \mathrm{Rb}^{+}$-occluded form by the introduction of an additional mutation of Tyr799Trp, which drives luminal gate closure, and consequently may stabilize the $\mathrm{K}^{+}$-occluded E2-AlF state (16). However, this quintuple mutant crystal did not diffract well, and produced only $20 \AA$ reflections (Table S1). We therefore determined its structure by cryo-EM, and obtained a $2.6 \AA$ resolution structure in the presence of the transition state phosphate analog $\mathrm{AlF}_{4}^{-}$and $100 \mathrm{mM} \mathrm{KCl}$ (Fig. 6, Fig. S2, Table S4).

As expected, enhanced hydrophobic interactions between the introduced Tyr799Trp and surrounding residues induced luminal gate closure, and the molecular conformation of the quintuple mutant Lys791Ser/Glu820Asp/Tyr340Asn/Glu936Val/Tyr799Trp adopted the $\mathrm{K}^{+}$-occluded E2-AlF transition state (Fig. 6F). Its EM map now unambiguously showed two spherical densities at the cation-binding site, highly likely representing two $\mathrm{K}^{+}$ions (Fig 6B). The positions of these densities are very close to the site I and site II $\mathrm{K}^{+} \mathrm{s}$ in NKA in the same conformation (Fig. 6G,H). Considering the strong $\mathrm{Rb}^{+}$anomalous signal observed 
in the HKA quadruple mutant crystal structure in its luminal-open configuration (Fig. 4F), luminal gate closure by the luminal portion of TM4 in the quintuple mutant must push the $\mathrm{K}^{+}$in the TM5 direction, to give appropriate $\mathrm{K}^{+}$coordination, and thus two $\mathrm{K}^{+}$ions are observed as discrete densities (Fig. 6E,F). Satisfyingly, in the quintuple mutant structure, Asp824 now makes a hydrogen bond with Lys791Ser (3.0尺), and fixes the Lys791Ser position suitable for $\mathrm{K}^{+}$-coordination $(2.7 \AA)$ as seen in the NKA structure.

Total valence (Table S5) for $\mathrm{K}^{+}$calculated from the distance between $\mathrm{K}^{+}$and surrounding oxygen atoms showed acceptable values for $\mathrm{K}^{+}$coordination at site I (0.65) and site II (0.68). The values are comparable at site II of NKA (0.64), but lower than at site I (1.06). The different valence at site I is largely due to the presence of a water molecule in NKA (Fig. $6 \mathrm{G}, \mathrm{H}$ ), which coordinates $\mathrm{K}^{+}$at $2.6 \AA$ (partial valence is 0.30 ). This water is absent, at least invisible, in the cryo-EM map of the HKA quintuple mutant. Instead, an Asp824 oxygen weakly coordinates $\mathrm{K}^{+}$in the HKA quintuple mutant $(3.1 \AA)$. Except for this water molecule, $\mathrm{K}^{+}$-coordination in the HKA quintuple mutant is almost identical to that in the $\mathrm{NKA} \mathrm{K}^{+}$-occlusion state.

In our previous study, we found that the Tyr799Trp mutation shows a characteristic inverse $\mathrm{K}^{+}-$ dependence in its ATPase activity profile (Fig. 2D). This was interpreted as gate closure in the TM helices being transmitted to the A domain, and in turn inducing spontaneous E2P dephosphorylation without $\mathrm{K}^{+}$binding (16). Therefore, it is unlikely that the ATP hydrolysis of the Try799Trp mutant couples with cation transport, and thus this enzyme exhibits a futile ATP-consuming activity in the absence of $\mathrm{K}^{+}$. Interestingly, however, despite having the Tyr799Trp mutation, the quintuple mutant clearly showed a $\mathrm{K}^{+}$-dependent increase in its ATPase activity (Fig. 2I). Although, the $\mathrm{K}^{+}$-independent ATPase activity is approximately $30 \%$ of the full activity, the $\mathrm{K}^{+}$-dependent fraction is likely coupled with cation transport. If so, how much of a cation gradient can the quintuple mutant form? The answer is probably a rather low gradient, if any at all, both because of the two transported $\mathrm{K}^{+}$and limited free energy from ATP hydrolysis (16) and the absence the salt bridge between Lys791 and Glu820, which appears necessary for $\mathrm{H}^{+}$extrusion to the stomach lumen (4).

\section{Conclusion}

Starting from a single- $\mathrm{K}^{+} \mathrm{HKA}$ wild type as template, we succeeded in generating an HKA mutant with two bound/occluded $\mathrm{K}^{+} \mathrm{s}$ by introducing five mutations. Our stepwise introduction of HKA mutations indicates that cation coordination in P2-type pumps is not simply defined by the primary coordinating amino acids, but in fact secondary and remote higher-order interactions, as well as the obvious need for space, come into play. Creation of the second binding site required a minimum of four mutations, namely, Lys791Ser and Glu820Asp to let up space and provide coordinating oxygens, Tyr340Asn to change the rotamer conformation of coordinating Asn792, and Glu936Val to modulate the Lys791Ser position indirectly via its hydrogen-bonding partner Asp824. Full gain-of-function and occlusion of two $\mathrm{K}^{+}$also needed conformationmodulating mutation Tyr799Trp, that stabilizes closure of the luminal gate and occlusion. Our approach of gradual and tailored construction of the second $\mathrm{K}^{+}$binding site provides important insights into the molecular basis of the different $\mathrm{K}^{+}$stoichiometries of the two closely-related cation pumps, $\mathrm{H}^{+}, \mathrm{K}^{+}$-ATPase and $\mathrm{Na}^{+}, \mathrm{K}^{+}-$ ATPase.

\section{Materials and Methods \\ Chemical and other reagents}

Unless otherwise noted, chemicals were from Wako and Sigma. BYK99 was a gift from Dr. K. Munson (UCLA). Cell culture media Pro293S was from Lonza and FreeStyle293 from Thermo. Superose6Increase column came from Cytiva.

\section{Protein expression and purification}

Procedures for protein expression are essentially the same as those reported previously (20). Briefly, the Flag epitope tag (DYKDDDDK), hexa-histidine tag, and the enhanced green fluorescence protein (EGFP) followed by a tobacco etch virus (TEV) protease recognition sequence were attached to the amino terminal of Met 48 of the pig gastric HKA $\alpha$-subunit mutants and cloned into a hand-made vector based on a previous report (4). The pig gastric HKA $\beta$-subunit (wild type) was also cloned independently. The $\alpha \beta$ complex of HKA was expressed in the plasma membrane using baculovirus-mediated transduction of 
mammalian HEK293S GnT1- cells purchased from ATCC (24). The harvested cells were broken up using a high-pressure emulsifier, and membrane fractions were sedimented. Membrane fractions were solubilized with $1 \%$ octaethylene glycol monododecyl ether $\left(\mathrm{C}_{12} \mathrm{E}_{8}\right.$, Nikko Chemical) with $40 \mathrm{mM}$ MES/Tris (pH 6.5), $10 \%$ glycerol, $5 \mathrm{mM}$ dithiothreitol in the presence of $100 \mathrm{mM} \mathrm{RbCl}, 1 \mathrm{mM} \mathrm{MgCl}_{2}, 1 \mathrm{mM} \mathrm{BeSO}_{4}, 3 \mathrm{mM}$ $\mathrm{NaF}$ and $10 \mathrm{mM} \mathrm{BYK} 99$, on ice for $20 \mathrm{~min}$. Proteins were affinity purified by anti-Flag M2 affinity resin (Sigma), which was followed by digestion of affinity tag and deglycosylation by TEV protease and MBPfusion endoglycosidase (New England Biolabs), respectively, at $4{ }^{\circ} \mathrm{C}$ overnight. Samples were further purified by a size-exclusion column chromatograph (SEC) using a Superose6 Increase column (Cytiva). Peak fractions were collected and concentrated to $10 \mathrm{mg} / \mathrm{ml}$. The concentrated HKA samples were added to glass tubes in which a layer of dried dioleoyl phosphatidylcholine had formed, in a lipid-to-protein ratio of $0.1-0.4$, and incubated overnight at $4{ }^{\circ} \mathrm{C}$ in a shaker mixer operated at $120 \mathrm{rpm}$ (25). After removing the insoluble material by ultracentrifugation, the lipidated samples were used for the crystallization.

For cryo-EM analysis, cells expressing quintuple mutant were directly solubilized with $1 \%$ lauryl maltose neopentyl glycol (LMNG) in the presence of $40 \mathrm{mM}$ MES/Tris (pH 6.5), 10\% glycerol, $5 \mathrm{mM}$

dithiothreitol, $100 \mathrm{mM} \mathrm{KCl}, 1 \mathrm{mM} \mathrm{MgCl}, 1 \mathrm{mM} \mathrm{AlCl} 3,4 \mathrm{mM} \mathrm{NaF}$, on ice for $20 \mathrm{~min}$. After removing insoluble material, proteins were affinity-purified as described above, except for exchanging the detergent with $0.06 \%$ glycerol-diogenin (GDN) at the washing stage, and following SEC separation. Peak fractions in the SEC separation were concentrated to $10 \mathrm{mg} / \mathrm{ml}$ and used for the cryo-EM grid preparations.

\section{Crystallization and structural determination}

Crystals were obtained by vapor diffusion at $20{ }^{\circ} \mathrm{C}$. A $5-\mathrm{mg} / \mathrm{ml}$ purified, lipidated protein sample was mixed with reservoir solution containing 10\% glycerol, $18-20 \%$ PEG2000MME, $3 \%$ methylpentanediol, and $5 \mathrm{mM} \beta$-mercaptoethanol in the presence of $0.2 \mathrm{M} \mathrm{RbCl}$ for all mutants evaluated in this study. Crystals were flash frozen in liquid nitrogen.

Diffraction data were collected at the SPring- 8 beamline BL41XU and BL45XU, and processed using Kamo (26) and XDS (27). Structure factors were subjected to anisotropy correction using the UCLA MBI Diffraction Anisotropy server (28) (http://services.mbi.ucla.edu/anisoscale/). The structures were determined by molecular replacement with PHASER, using an atomic model of $\mathrm{H}^{+}, \mathrm{K}^{+}$-ATPase in the SCH28080-bound E2BeF state (pdb ID: 5YLV) as a search model. Coot (29) was used for cycles of iterative model building and Refmac5 and Phenix (30) were used for refinement. Rubidium ions were identified in anomalous difference Fourier maps calculated using data collected at wavelengths of $0.8147 \AA$. The KS/ED mutant structure was not refined due to its limited resolution. The KS, KS/ED/YN and $\mathrm{KS} / \mathrm{ED} / \mathrm{YN} / \mathrm{EV}$ mutant models contained $93.4 / 6.6 / 0.0 \%, 94.8 / 5.2 / 0.0 \%$ and $97.3 / 2.7 / 0.0 \%$ in the favored, allowed, and outlier regions of the Ramachandran plot, respectively. Note the diffraction data from multiple crystals were merged by Kamo for the native data set of the KS and KS/ED/YN mutant, while others, including the $\mathrm{Rb}^{+}$anomalous data set for wild type and all the mutants, were corrected from the single crystal.

\section{Cryo-EM analysis}

Preparation of sample and cryo-EM grid was done according to the previous report (31). The purified protein samples (final protein concentration of $10 \mathrm{mg} / \mathrm{ml}$ ) were applied to a freshly glow-discharged Quantifoil holey carbon grid (R1.2/1.3, Cu/Rh, 300 mesh), using a Vitrobot Mark IV (FEI) at $4{ }^{\circ} \mathrm{C}$ with a blotting time of $8 \mathrm{~s}$ under $99 \%$ humidity condition, and the grids were then plunge-frozen in liquid ethane. The prepared grids were transferred to a Titan Krios G4i microscope (Thermo Fisher Scientific), running at $300 \mathrm{kV}$ and equipped with a Gatan Quantum-LS Energy Filter (GIF) and a Gatan K3 Summit direct electron detector in the electron counting mode. Imaging was performed at a nominal magnification of $105,000 x$, corresponding to a calibrated pixel size of $0.83 \AA /$ pix (The University of Tokyo, Japan). Each movie was recorded in a correlated-double sampling (CDS) mode for $2.3 \mathrm{~s}$ and subdivided into 64 frames. The electron flux was set to $7.5 \mathrm{e}$-/pix/s at the detector, resulting in an accumulated exposure of $64 \mathrm{e}^{-} / \AA^{2}$ at the specimen. The data were automatically acquired by the image shift method using SerialEM software (32), with a defocus range of -0.8 to $-1.6 \mu \mathrm{m}$. The dose-fractionated movies were subjected to beam- 
induced motion correction, using MotionCor2 (33) or Relion (34), and the contract transfer function (CTF) parameters were estimated using CTFFIND4 (35).

For each dataset, particles were initially picked by using EMAN2.2 (36), and extracted with downsampling to a pixel size of $3.24 \AA /$ pix. These particles were subjected to several rounds of $2 \mathrm{D}$ and $3 \mathrm{D}$ classifications. The best class was then re-extracted with a pixel size of $0.83 \AA /$ pix and subjected to 3D refinement. The resulting 3D model and particle set were subjected to per-particle defocus refinement, beam-tilt refinement, Bayesian polishing (37), and 3D refinement. Resolution of the analyzed map is defined according to the FCS $=0.143$ criterion (Fig. S2) (38). The local resolution and angular distributions for each structure were estimated by Relion (Figure S2).

\section{ATPase activity assay using membrane fractions of recombinant proteins}

$\mathrm{N}$-terminal GFP-tagged and N-terminal deletion $(\Delta 48)$ wild type or mutant $\alpha$-subunit used for the structural analysis was co-expressed with the wild type $\beta$-subunit using the BacMam system as described above, and broken membrane fractions were collected. $\mathrm{H}^{+}, \mathrm{K}^{+}$-ATPase activity was measured as described previously (20). Briefly, permeabilized membrane fractions (wild type or mutant) were suspended in buffer comprising $40 \mathrm{mM}$ PIPES/Tris (pH 7.0), $2 \mathrm{mM} \mathrm{MgCl}_{2}, 2 \mathrm{mM} \mathrm{ATP}$, and 0-200 $\mathrm{mM} \mathrm{KCl}$ in the presence or absence of $10 \mu \mathrm{M}$ vonoprazan, in 96-well microtubes. Reactions were initiated by incubating the fractions at $37^{\circ} \mathrm{C}$ using a thermal cycler, and maintained for 1 to $3 \mathrm{~h}$ depending on their activity. Reactions were terminated, and the amount of released inorganic phosphate was determined colorimetrically using a microplate reader (TECAN). To compare the relative turnover number of the mutants, the amount of HKA in the membrane fractions was determined by monitoring the fluorescence from $\mathrm{N}$-terminally attached GFP fluorescence using $\operatorname{HPLC}(31,39)$ as performed previously. Membrane fractions used for the ATPase assay were solubilized by $1 \% \mathrm{LMNG}$ in the presence of $40 \mathrm{mM}$ PIPES/Tris ( $\mathrm{pH} 7.0), 10 \%$ glycerol, $2 \mathrm{mM}$ $\mathrm{MgCl}_{2}, 1 \mathrm{mM} \mathrm{BeSO}_{4}$ and $3 \mathrm{mM} \mathrm{NaF}$, and the approximate contents of the $\alpha \beta$-complex per $\mathrm{mg}$ membrane fractions were determined. These values were used for the normalization of ATPase activities for the evaluated mutants and are shown in Table S2.

\section{Thermal stability assay}

Membrane fractions $(1 \mathrm{mg} / \mathrm{ml})$ expressing wild type or indicated mutants HKA were solubilized for $20 \mathrm{~min}$ on ice with a buffer containing $1 \% \mathrm{C}_{12} \mathrm{E}_{8}, 40 \mathrm{mM}$ HEPES/Tris ( $\mathrm{pH} 6.5$ ), $10 \%$ glycerol, $1 \mathrm{mM} \mathrm{MgCl}_{2}$ in the presence of $1 \mathrm{mM} \mathrm{BeSO}, 3 \mathrm{mM} \mathrm{NaF}, 0.1 \mathrm{mM} \mathrm{SCH} 28080$ (for BeF + SCH28080) or $1 \mathrm{mM} \mathrm{AlCl}_{3}, 4 \mathrm{mM}$ $\mathrm{NaF}$ and $100 \mathrm{mM} \mathrm{RbCl}$ (for $\mathrm{AlF}+\mathrm{Rb}^{+}$) in a volume of $0.25 \mathrm{~mL}$. Insoluble material in the samples was removed by ultracentrifugation, and the obtained supernatants $(16 \mathrm{ml})$ were incubated for $10 \mathrm{~min}$ at indicated temperatures using a thermal cycler. Samples were diluted ten-fold with ice-cold buffer containing $40 \mathrm{mM} \mathrm{HEPES} /$ Tris ( $\mathrm{pH} 6.5$ ), $1 \%$ glycerol, $50 \mathrm{mM} \mathrm{NaCl}$ and $0.03 \% \mathrm{C}_{12} \mathrm{E}_{8}$, denatured proteins again removed by ultracentrifugation, and evaluated by fluorescence size-exclusion chromatography (40). Peak values in each sample were plotted as a function of the treated temperature, and determined their $T_{\mathrm{m}}$ determined by sigmoidal curve fit (PRISM4).

PDB

7EFL : Crystal structure of the gastric proton pump K791S mutant in Rb+-bound (BYK)E2BeF state 7EFM: Crystal structure of the gastric proton pump K791S/E820D/Y340N mutant in Rb+-bound (BYK)E2BeF state

7EFN: Crystal structure of the gastric proton pump K791S/E820D/Y340N/E936V mutant in Rb+-bound (BYK)E2BeF state

7ET1: Cryo-EM structure of the gastric proton pump K791S/E820D/Y340N/E936V/Y799W mutant in K+occluded $(\mathrm{K}+) \mathrm{E} 2$-AlF state

EMDB-31294

Cryo-EM structure of the gastric proton pump K791S/E820D/Y340N/E936V/Y799W mutant in K+occluded $(\mathrm{K}+)$ E2-AlF state 


\section{Acknowledgments}

We thank Dr. P. Artigas at TTUHSC for valuable comments on the manuscript, Dr. D. McIntosh for improving the manuscript. The synchrotron radiation experiments were performed at BL41XU and BL45XU in SPring-8 with the approval of the Japan Synchrotron Radiation Research Institute (JASRI Proposal numbers: 2019B2707 and 2021B2716). We thank beamline staff for their facilities and support. This research is partly supported by the Platform Project for Supporting Drug Discovery and Life Science Research (Basis for Supporting Innovative Drug Discovery and Life Science Research (BINDS)) from AMED under Grant Number JP19am0101115j0003 (support number 1925).

Author Contributions: K.A. conceptualization; K.A., K.Y. performed protein purification, crystallization, and crystal data collection; K.A. and A.O. cryo-EM grid preparation; K.A. and T.N. cryo-EM data acquisition; K.A. K.Y. and K.I crystallographic analysis; K.A., A.O. and T.N. cryo-EM processing; K.A. writing-original draft; K.A., K.I. writing-review and editing; K.A. supervision; K.A. and A.O. funding acquisition; K.A. project administration.

Competing Interest Statement: Authors disclose no competing interests.

\section{References}

1. M. G. Palmgren, K. B. Axelsen, Evolution of P-type ATPases. Biochim. Biophys. Acta 1365, $37-45$ (1998).

2. C. Toyoshima, M. Nakasako, H. Nomura, H. Ogawa, Crystal structure of the calcium pump of sarcoplasmic reticulum Ê resolution. Nature 405, 647-655 (2000).

3. J. P. Morth, et al., Crystal structure of the sodium-potassium pump. Nature 450, 1043-1049 (2007).

4. K. Abe, K. Irie, H. Nakanishi, H. Suzuki, Y. Fujiyoshi, Crystal structures of the gastric proton pump. Nature 556, 214-229 (2018).

5. R. L. Post, S. Kume, T. Tobin, B. Orcutt, A. K. Sen, Flexibility of an active center in sodiumplus-potassium adenosine triphosphatase. J. Gen. Physiol. 54, 306-326 (1969).

6. R. W. Albers, Biochemical Aspects of Active Transport. Annu. Rev. Biochem. 36, 727-756 (1967).

7. E. C. Rabon, M. a Reuben, The mechanism and structure of the gastric H,K-ATPase. Annu. Rev. Physiol. 52, 321-44 (1990).

8. R. L. Post, S. Kume, Evidence for an Aspartyl Phosphate Residue at the Active Site of Sodium and Potassium Ion Transport Adenosine Triphosphatase Evidence of Sodium for an Aspartyl Potassium Phosphate Ion Transport Residue at the Active Site and Adenosine Triphospha. J. Biol. Chem. 248 (1973). 9. S. Danko, K. Yamasaki, T. Daiho, H. Suzuki, C. Toyoshima, Organization of cytoplasmic domains of sarcoplasmic reticulum Ca2+-ATPase in E1P and E1ATP states: A limited proteolysis study. FEBS Lett. 505, 129-135 (2001).

10. C. Toyoshima, Y. Norimatsu, S. Iwasawa, T. Tsuda, H. Ogawa, How processing of aspartylphosphate is coupled to lumenal gating of the ion pathway in the calcium pump. Proc. Natl. Acad. Sci. 104, 19831-19836 (2007).

11. S. Danko, K. Yamasaki, T. Daiho, H. Suzuki, Distinct natures of beryllium fluoride-bound, aluminum fluoride-bound, and magnesium fluoride-bound stable analogues of an ADP-insensitive phosphoenzyme intermediate of sarcoplasmic reticulum Ca2+-ATPase: Changes in catalytic and transport sites during ph. J. Biol. Chem. 279, 14991-14998 (2004).

12. C. T. Okamoto, S. Asano, H. Sakai, "The Cell Biology of Gastric Acid Secretion" in Physiology of the Gastrointestinal Tract: Sixth Edition, (Elsevier Inc., 2018), pp. 831-867.

13. J. M. Wolosin, Ion transport studies with $\mathrm{H}+-\mathrm{K}+-$ ATPase-rich vesicles : implications for $\mathrm{HCl}$ secretion and parietal cell physiology Ion transport studies with $\mathrm{H}+-\mathrm{K}+-\mathrm{ATPase}-\mathrm{rich}$ vesicles : 
implications for $\mathrm{HCl}$ secretion and parietal cell physiology. Am J Physiol Gastrointest Liver Physiol 248, G595-G607 (1985).

14. W. W. Reensta, J. Forte, H+/ATP stoichiometry for the gastric $(\mathrm{K}++\mathrm{H}+)$-ATPase. J. Membrne Biol 61, 55-60 (1997).

15. E. C. Rabon, T. L. Mcfall, G. Sachs, The Gastric [ H , K ] ATPase : H + / ATP Stoichiometry *. 257, 6296-6299 (1982).

16. K. Yamamoto, et al., A single k+-binding site in the crystal structure of the gastric proton pump. Elife 8 (2019).

17. P. L. Jorgensen, K. O. Håkansson, S. J. D. Karlish, Structure and Mechanism of Na,K-ATPase: Functional Sites and Their Interactions. Annu. Rev. Physiol. 65, 817-849 (2003).

18. T. Shinoda, H. Ogawa, F. Cornelius, C. Toyoshima, Crystal structure of the sodium-potassium pump at $2.4 \AA$ resolution. Nature $459,446-450$ (2009).

19. K. L. Dürr, I. Seuffert, T. Friedrich, Deceleration of the E1P-E2P transition and ion transport by mutation of potentially salt bridge-forming residues Lys-791 and Glu-820 in gastric H+/K+-ATPase. J. Biol. Chem. 285, 39366-39379 (2010).

20. K. Abe, et al., The cryo-EM structure of gastric $\mathrm{H}+, \mathrm{K}+-\mathrm{ATPase}$ with bound BYK99, a highaffinity member of K+-competitive, imidazo[1,2-a]pyridine inhibitors. Sci. Rep. 7 (2017).

21. M. Laursen, J. L. Gregersen, L. Yatime, P. Nissen, N. U. Fedosova, Structures and characterization of digoxin- and bufalin-bound $\mathrm{Na}+, \mathrm{K}+$-ATPase compared with the ouabain-bound complex. Proc. Natl. Acad. Sci. 112, 1755-1760 (2015).

22. N. Tsunekawa, H. Ogawa, J. Tsueda, T. Akiba, C. Toyoshima, Mechanism of the E2 to E1 transition in $\mathrm{Ca} 2+$ pump revealed by crystal structures of gating residue mutants [Biochemistry]. Proc. Natl. Acad. Sci. U. S. A. 115, 2-7 (2018).

23. R. Blostein, A. Wilczynska, S. J. D. Karlish, J. M. Argüello, J. B. Lingrel, Evidence that Set775 in the $\alpha$ subunit of the Na,K-ATPase is a residue in the cation binding pocket. J. Biol. Chem. 272, 2498724993 (1997).

24. A. Goehring, et al., Screening and large-scale expression of membrane proteins in mammalian cells for structural studies. Nat. Protoc. 9, 2574-2585 (2014).

25. P. Gourdon, et al., HiLiDe-systematic approach to membrane protein crystallization in lipid and detergent. Cryst. Growth Des. 11, 2098-2106 (2011).

26. K. Yamashita, K. Hirata, M. Yamamoto, KAMO: towards automated data processing for microcrystals. Acta Crystallogr. Sect. D Struct. Biol. 74, 441-449 (2018).

27. W. Kabsch, et al., XDS. Acta Crystallogr. Sect. D Biol. Crystallogr. 66, 125-132 (2010).

28. G. K. Ackers, J. M. Holt, Asymmetric cooperativity in a symmetric tetramer: Human hemoglobin. J. Biol. Chem. 281, 11441-11443 (2006).

$29 . \quad$ P. Emsley, et al., Coot : model-building tools for molecular graphics. Acta Crystallogr. Sect. D Biol. Crystallogr. 60, 2126-2132 (2004).

$30 . \quad$ P. D. Adams, et al., PHENIX: a comprehensive Python-based system for macromolecular structure solution. Acta Crystallogr. D. Biol. Crystallogr. 66, 213-21 (2010).

31. H. Nakanishi, et al., Transport Cycle of Plasma Membrane Flippase ATP11C by Cryo-EM. Cell Rep. 32, 108208 (2020).

32. D. N. Mastronarde, Automated electron microscope tomography using robust prediction of specimen movements. J. Struct. Biol. 152, 36-51 (2005).

33. X. Li, et al., Electron counting and beam-induced motion correction enable near-atomicresolution single-particle cryo-EM. Nat. Methods 10, 584-590 (2013).

34. J. Zivanov, et al., New tools for automated high-resolution cryo-EM structure determination in RELION-3. Elife 7 (2018).

35. A. Rohou, N. Grigorieff, CTFFIND4: Fast and accurate defocus estimation from electron micrographs. J. Struct. Biol. 192, 216-221 (2015).

36. G. Tang, et al., EMAN2: An extensible image processing suite for electron microscopy. J. Struct. Biol. 157, 38-46 (2007). 
37. J. Zivanov, T. Nakane, S. H. W. Scheres, A Bayesian approach to beam-induced motion correction in cryo-EM single-particle analysis. IUCrJ 6, 5-17 (2019).

38. P. B. Rosenthal, R. Henderson, Optimal determination of particle orientation, absolute hand, and contrast loss in single-particle electron cryomicroscopy. J. Mol. Biol. 333, 721-745 (2003).

39. H. Nakanishi, et al., Crystal structure of a human plasma membrane phospholipid flippase. J. Biol. Chem. 295, 10180-10194 (2020).

40. M. Hattori, R. E. Hibbs, E. Gouaux, A fluorescence-detection size-exclusion chromatographybased thermostability assay for membrane protein precrystallization screening. Structure 20, 1293-1299 (2012). 
Figures and Tables

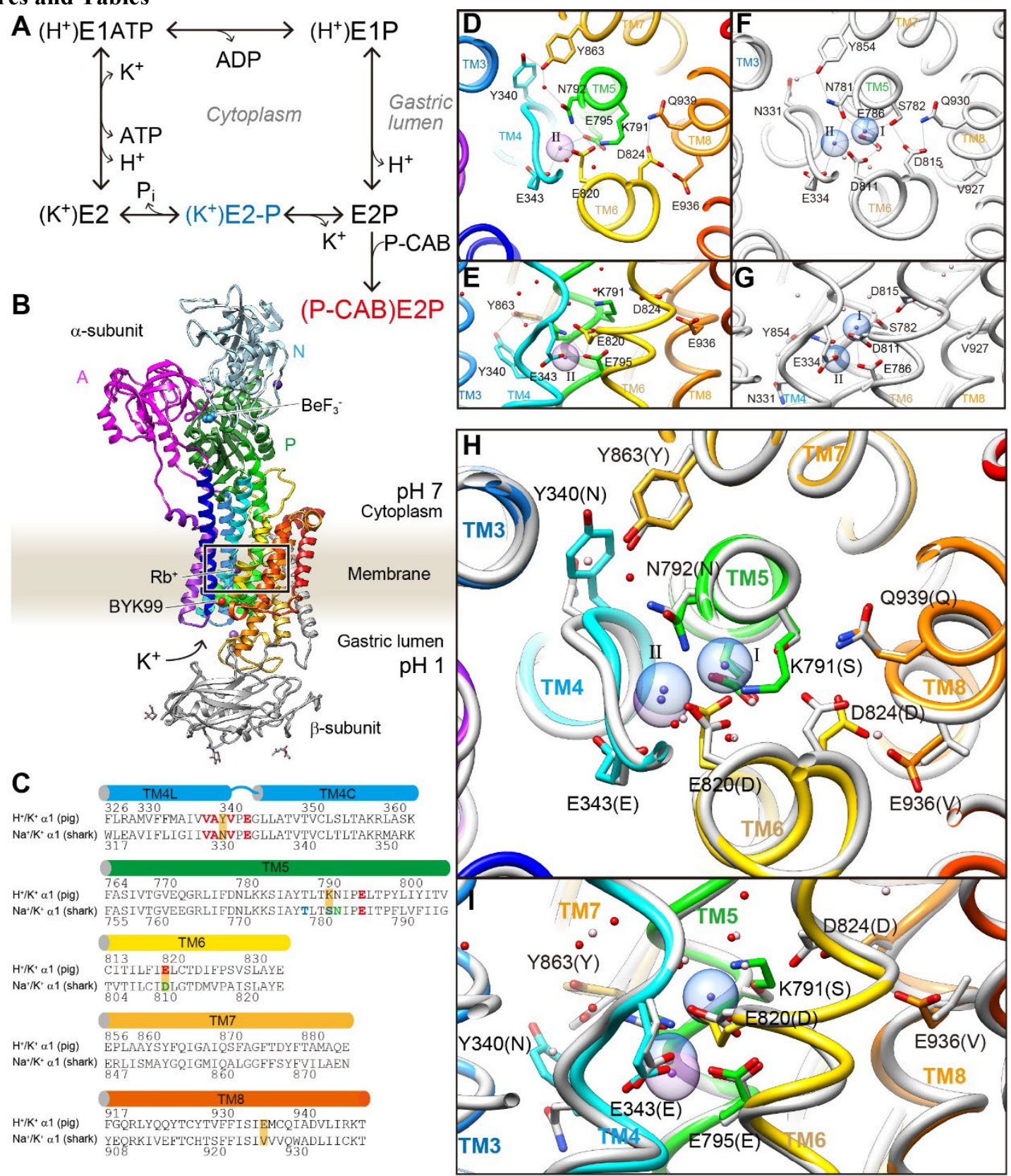

Figure 1. Comparison of the primary and tertiary structures of HKA and NKA.

A, The reaction cycle of HKA. P-CAB $\left(\mathrm{K}^{+}\right.$-competitive acid blockers) preferentially bind to the luminalopen E2P state from the luminal side of the membrane, and inhibits the enzyme (red). E2P is labile in the presence of luminal $\mathrm{K}^{+}$, and proceeds to dephosphorylation. Transition state analog $\mathrm{AlF}_{4}^{-}$traps the enzyme in the $\mathrm{K}^{+}$-occluded $\left(\mathrm{K}^{+}\right) \mathrm{E} 2-\mathrm{P}$ transition state (blue). B, Overall structure of HKA Lys791Ser/Glu820Asp/Tyr340Asn/Glu936Val quadruple mutant in BYK99-bound E2BeF state, determined in this study in ribbon representations. For the $\alpha$-subunit, the three cytoplasmic domains (A, P and $\mathrm{N}$ ) are shown in different colors. The color of the TM helices gradually changes from purple to red (TM1-TM10). The $\beta$-subunit with a single TM helix and six $N$-glycosylation sites (three shown in sticks) in the ecto-domain is shown in grey. Blue and purple spheres represent $\mathrm{BeF}$ and $\mathrm{Rb}^{+}$, respectively. $\mathbf{C}$, 
Sequence alignment of a part of TM helices of HKA (pig) and NKA (shark). Amino acids shown in blue are involved in the $\mathrm{K}^{+}$coordination at site I, red for site II and green for both sites. Yellow boxes indicate amino acids evaluated in this study. D-I, Close-up view of the cation-binding sites of HKA $\left(\mathrm{K}^{+}\right) \mathrm{E} 2-\mathrm{MgF}$ state $(\mathbf{D}, \mathbf{E}, 6 \mathrm{jhx})$, NKA $\left(\mathrm{K}^{+}\right)_{2} \mathrm{E} 2-\mathrm{MgF}$ state $(\mathbf{F}, \mathbf{G}, 2 \mathrm{zxe})$ and their comparison $(\mathbf{H}, \mathbf{I})$. HKA is shown in color ribbons as indicated in $\mathbf{B}$, while NKA is in gray ribbons. $\mathrm{Rb}^{+}$(purple dot with transparent sphere indicating its ionic radius) in HKA and two $\mathrm{K}^{+}$ions at sites I and II in NKA (blue dot and spheres) are shown. Only amino acid residues focused on in this study are shown for clarity. Amino acids in NKA are indicated in parentheses. 

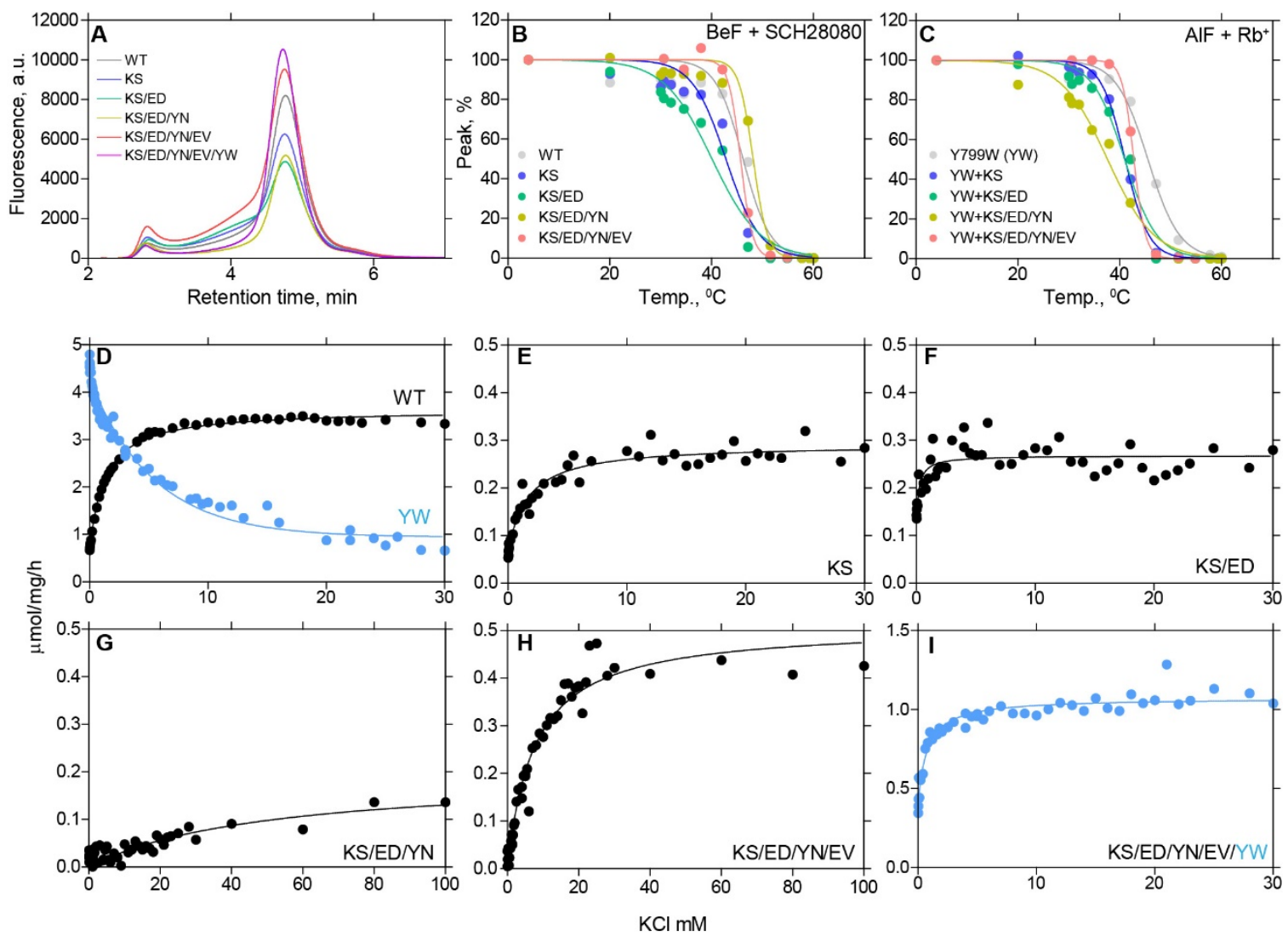

Figure 2. Thermal stabilities and $\mathrm{K}^{+}$-dependent ATPase activities of HKA mutants.

A, the expression levels of each mutant in their membrane fractions were determined by fluorescence sizeexclusion chromatography (FSEC). Membrane fractions were solubilized by LMNG in the presence of BeF and monitored by their GFP fluorescence. Peak value indicates relative contents of HKA wild type or mutants in the membrane fractions. B,C, thermal stabilities of wild type and indicated mutants of HKA in the presence of $\mathrm{BeF}$ and $\mathrm{SCH}_{2} 8080(\mathbf{B})$ or $\mathrm{AlF}_{4}{ }^{-}$and $100 \mathrm{mM} \mathrm{Rb}^{+}(\mathbf{C})$ were determined as described in the experimental procedures. Peak values in the FSEC analysis were plotted as a function of treatment temperature. Peak value of the sample kept on ice $\left(0^{\circ} \mathrm{C}\right)$ was set as $100 \%$, and the temperature giving $50 \%$ peak intensity was taken as $T_{\mathrm{m}}$ (Table S1). D-H, $\mathrm{K}^{+}$-dependent ATPase activity in the membrane fractions as described in the experimental procedures. Data were fitted to the Michalis-Menten equation with a background $\mathrm{H}^{+}$-ATPase activity measured at $0 \mathrm{mM} \mathrm{KCl}$. The ATPase activity in the presence of $10 \mathrm{mM}$ vonoprazan does not change over the evaluated concentrations of $\mathrm{K}^{+}$, and was set as a blank value. $V_{\max }$ and $K_{0.5, \mathrm{~K}+}$ are displayed in Table S2. 


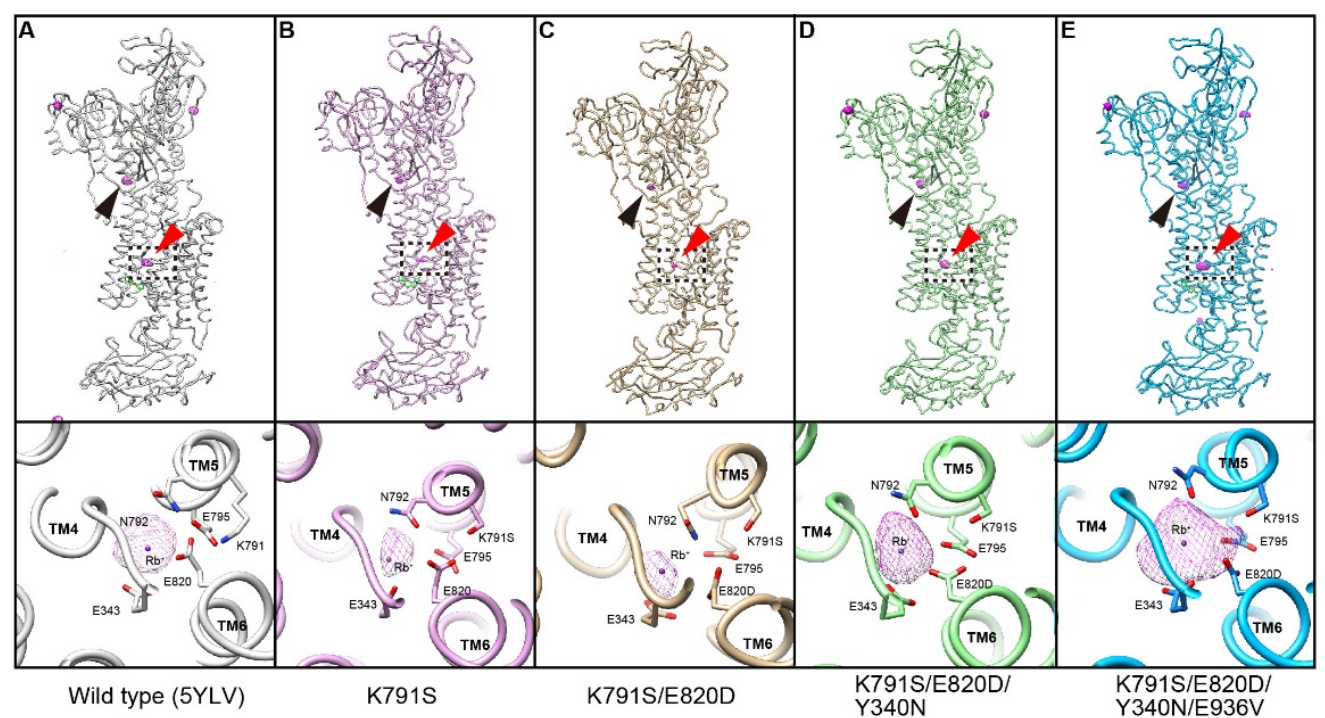

Figure 3. $\mathrm{Rb}^{+}$anomalous density maps.

A-E, Whole enzyme structures of wild type (A, 5ylv) and indicated mutants (B-E) are shown in the upper row. Close-up of the cation-binding sites (dotted boxes), viewed from the cytoplasmic side, are shown in the lower row. Purple mesh represents anomalous difference Fourier maps from $\mathrm{Rb}^{+}$in the asymmetric unit of the crystals, contoured at $4 \mathrm{~s}$. Anomalous densities responsible for the bound $\mathrm{Rb}^{+}$at the $\mathrm{TM}$ cationbinding site, and $\mathrm{P}$ domain are indicated as red and black arrowheads, respectively. 


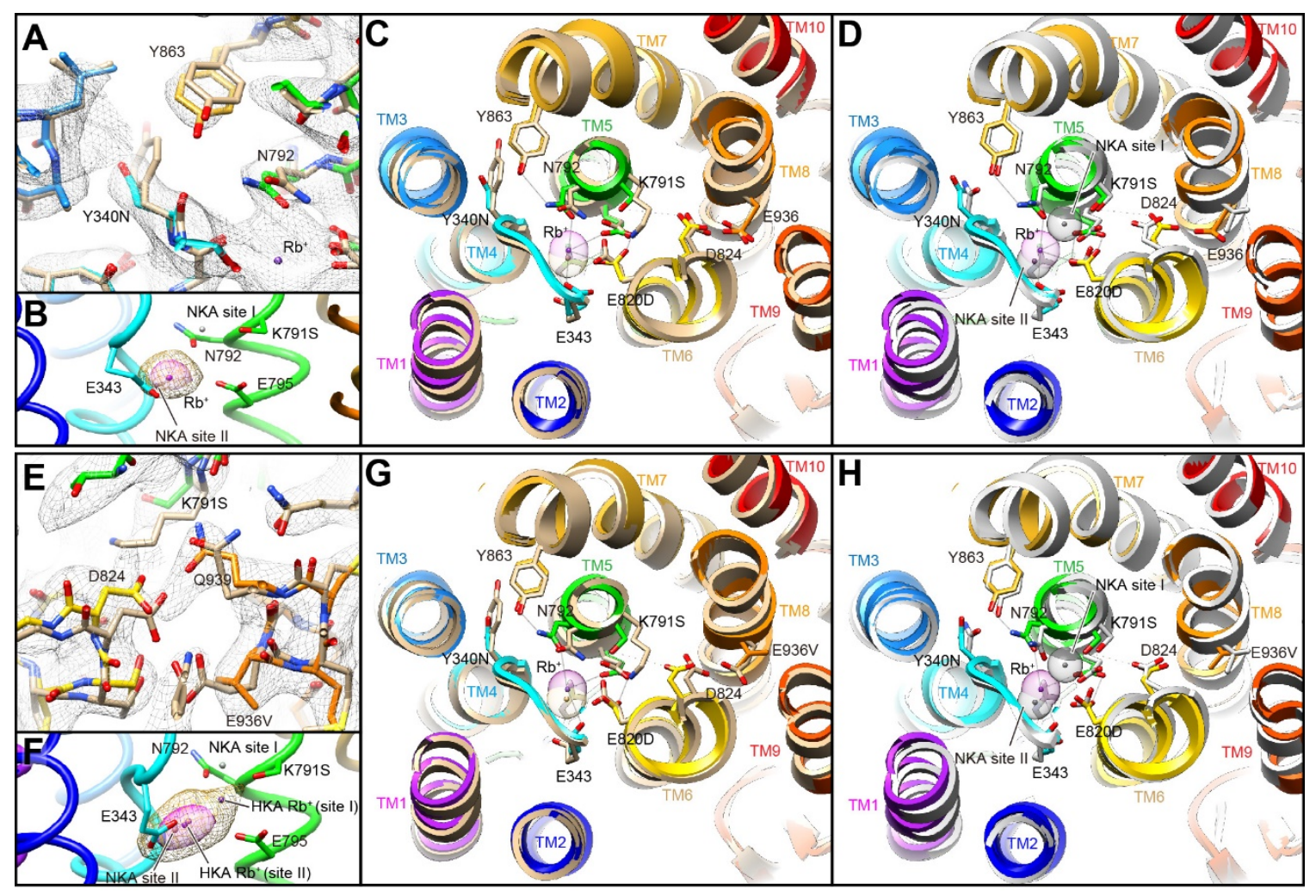

Figure. 4 Crystal structure of the KS/ED/YN triple and KS/ED/YN/EV quadruple mutant of HKA A,E, a 2 Fo-Fc electron density map around Tyr340Asn and Tyr836 of HKA triple mutant (A) and that around Asp824 and Glu936Val of HKA quadruple mutant (contoured at 1.5s) are shown in mesh representations. Color and wheat sticks represent mutants and wild type HKA, respectively. B,E, Purple surface (6s) and orange mesh (4s) represent the $\mathrm{Rb}^{+}$anomalous Fourier map at the cation-binding site, viewed along the membrane plane. Purple dots indicate the position of $\mathrm{Rb}^{+}$modeled in HKA triple mutant (B) or HKA quadruple mutant ( $\mathbf{E}$, both cases of one $\mathrm{Rb}^{+}$or two $\mathrm{Rb}^{+}$modeled were shown). Grey dots represent the two $\mathrm{K}^{+}$ions bound to site I and site II in the bufalin-bound NKA (4res) in both figures. $\mathbf{C , D}, \mathbf{G}, \mathbf{H}$, Cation-binding site structures of the triple $(\mathbf{C , D})$ and quadruple mutant $(\mathbf{G}, \mathbf{H})$, viewed from the cytoplasmic side, are shown with superimposed HKA wild type (C,G, 5ylv show in wheat) or NKA (D,H, 4res, shown in gray), respectively. Residues that likely form hydrogen bonds or contribute to the $\mathrm{Rb}^{+}$ coordination in the triple and quadruple mutant are connected with gray lines (within $3.5 \AA$ ). Dotted grey

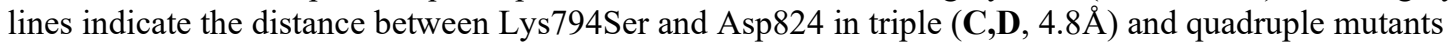
$(\mathbf{G}, \mathbf{H}, 4.1 \AA)$, respectively 


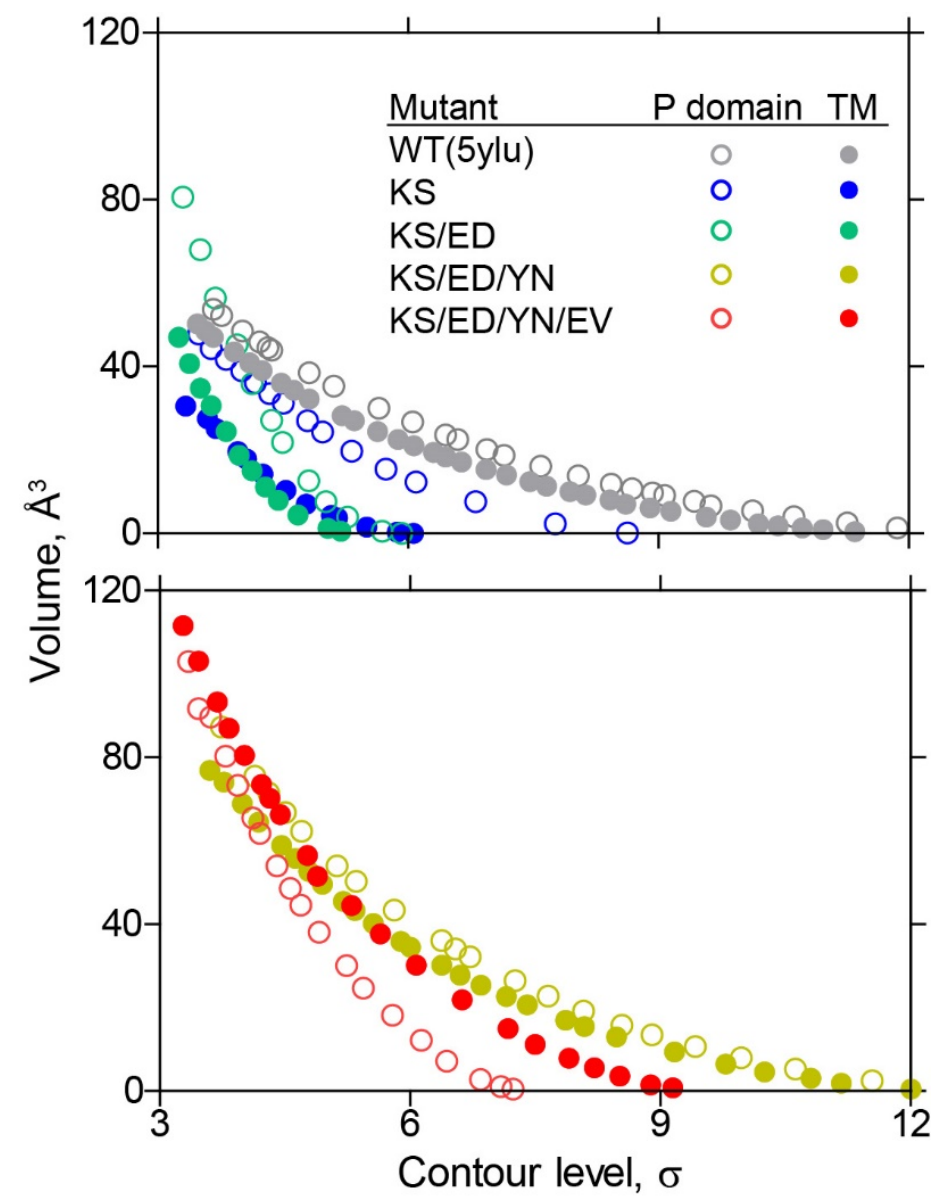

Figure 5. Trends in the anomalous $\mathrm{Rb}^{+}$densities

Volumes of the $\mathrm{Rb}^{+}$anomalous densities $\left(\AA^{3}\right)$ observed at the peripheral of the $\mathrm{P}$ domain (open symbols, black arrowheads in Fig. 3) and in the TM cation-binding site (closed symbols, red arrowheads in Fig. 3) for wild type (WT, 5ylu) and indicated mutants were plotted against their contour levels (in s). 

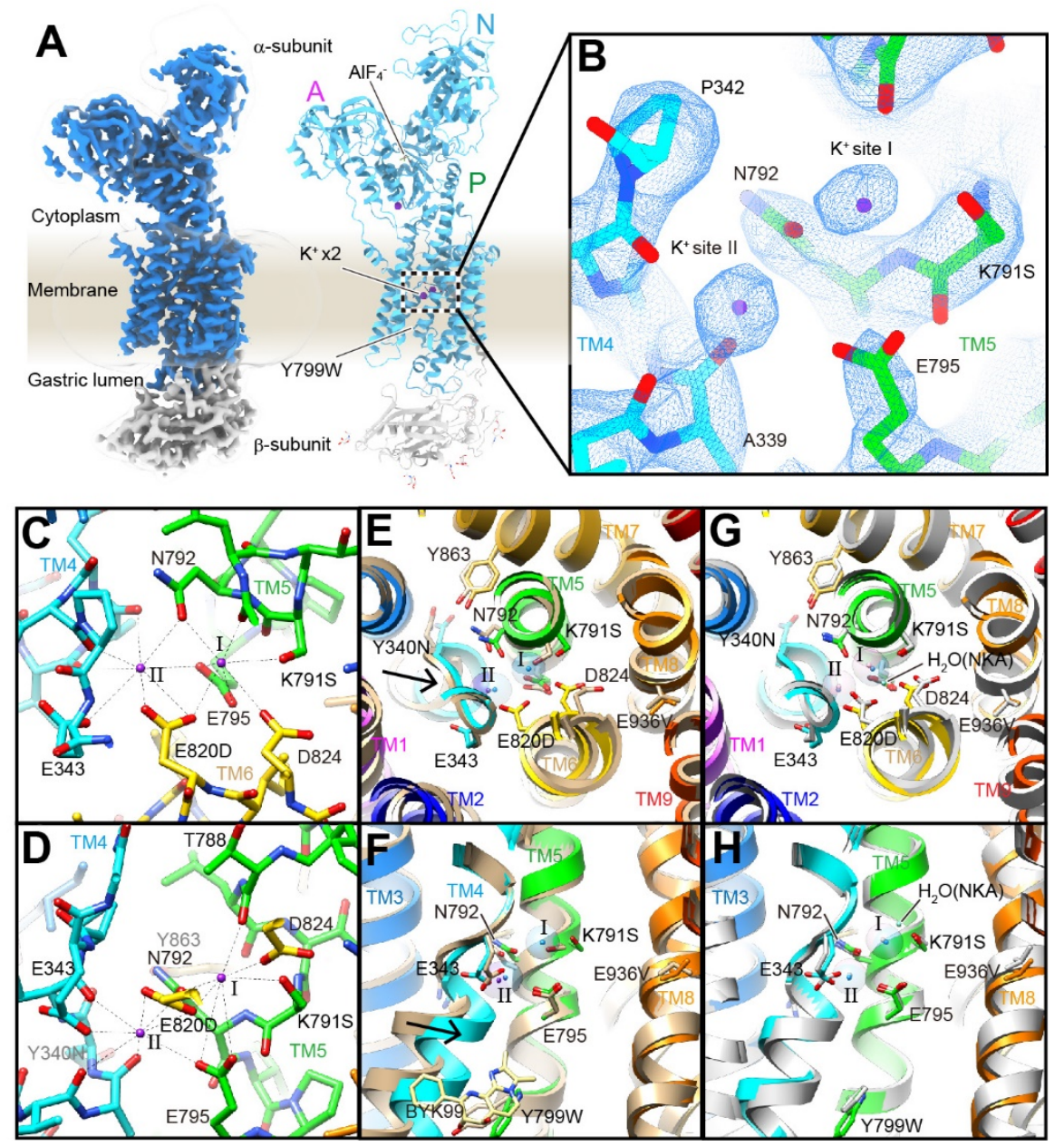

Figure 6. Cryo-EM structure of the two- $\mathrm{K}^{+}$occluded quintuple mutant.

A, Cryo-EM density map (left, blue and grey surface) and amino acid model (right, ribbons) of a quintuple mutant in the $\mathrm{K}^{+}$-occluded E2-AlF state. Transparent surface represents micelle and molecular envelope observed at lower contour level. Key amino acids, phosphate analog $\mathrm{AlF}_{4}^{-}$, and glycans attached at the $\beta$ subunit are shown as sticks. B, close-up view of two $\mathrm{K}^{+}$ions occluded at the cation-binding site in the membrane (dotted box in A). Blue mesh represents EM density map. C,D, $\mathrm{K}^{+}$-coordination in detail. Dotted lines connect $\mathrm{K}^{+}$ions (sites I and II) and coordinating oxygen atoms (see Table S5 for more details). E-H, structural comparisons between $\mathrm{K}^{+}$-occluded E2-AlF state of the HKA quintuple mutant (color ribbons) and luminal-open BYK99-bound E2BeF state of the HKA quadruple mutant (E,F, wheat ribbons) or NKA wild type in the $\mathrm{K}^{+}$-occluded $\mathrm{E} 2-\mathrm{MgF}$ state $(\mathbf{G}, \mathbf{H}$, grey ribbons, PDB 2zxe). Black arrows in $\mathbf{E}, \mathbf{F}$, indicate luminal gate closure upon $\mathrm{E} 2 \mathrm{BeF} \rightarrow \mathrm{E} 2-\mathrm{AlF}$ transition which occurs mostly at the luminal portion of TM4. Figures are viewed from the cytoplasmic side $(\mathbf{C , E}, \mathbf{G})$ or from a viewpoint parallel to the membrane plane with cytoplasmic side up $(\mathbf{D}, \mathbf{F}, \mathbf{H})$. 

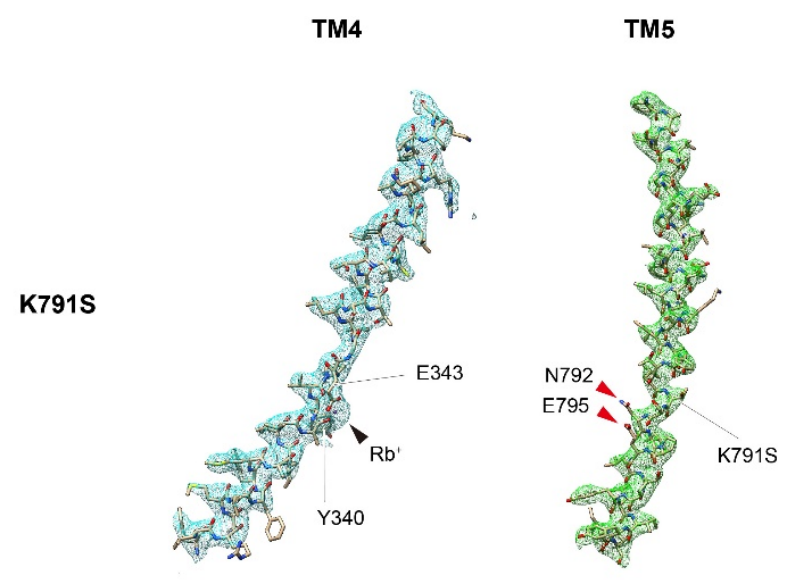

TM6

BYK99
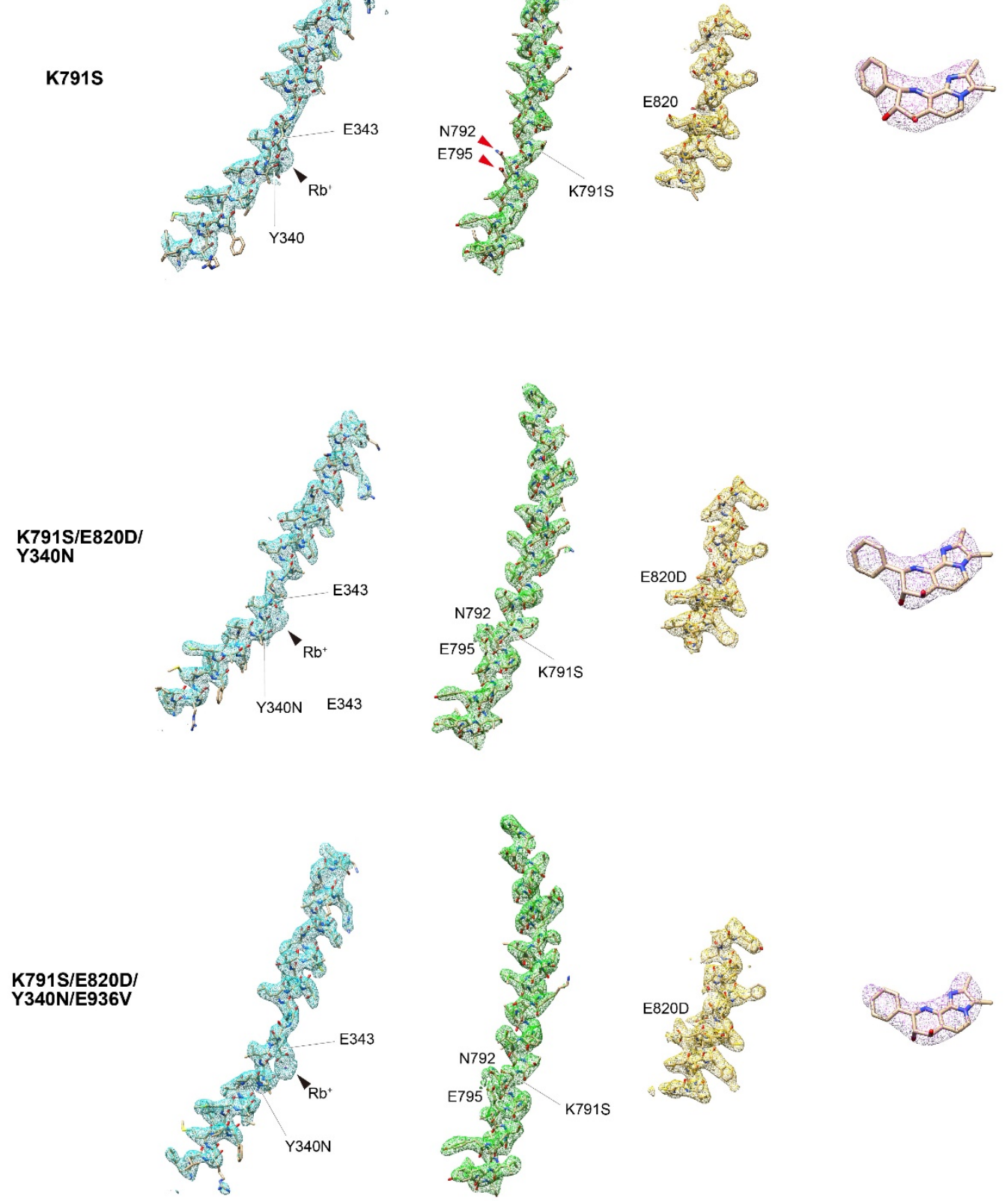

Figure S1. Electron density maps for the TM helices and bound BYK99 of HKA mutants. Mesh represents $2 \mathrm{Fo}-\mathrm{Fc}$ electron density maps around the indicated portion of the mutant enzymes contoured at $2 \mathrm{~s}$ level. Black arrowheads indicate $\mathrm{Rb}^{+}$at the cation-binding site. Red arrowheads indicate residues with poor density in the KS single mutant. 
A
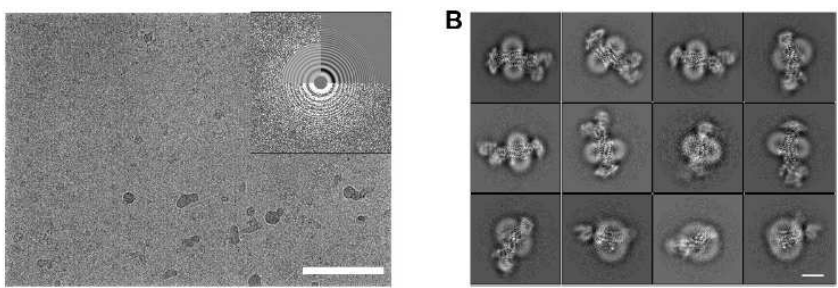

C

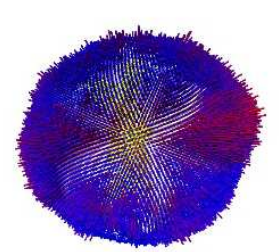

D

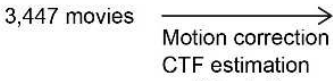

794,705 particles CTF estimation particle picking
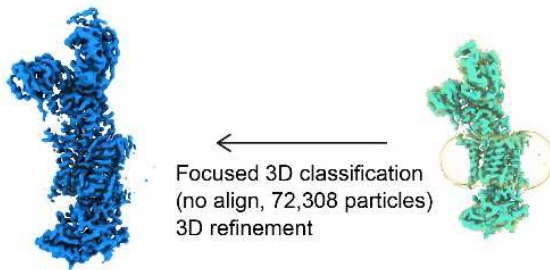

$3 \mathrm{D}$ refinement

E

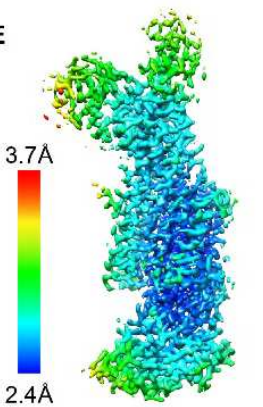

$\mathbf{F}$

\section{TM4}

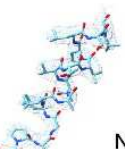
Y340N

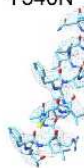

$\underset{2 D \text { classification }}{\longrightarrow} 355,395$ particles

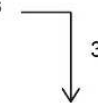

3D classification
3D refinement
CTF refinement Bayesian polishing
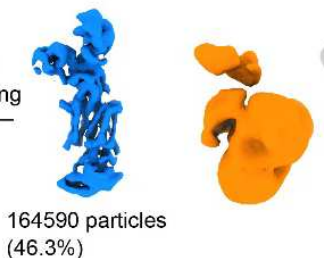

(46.3\%)

G
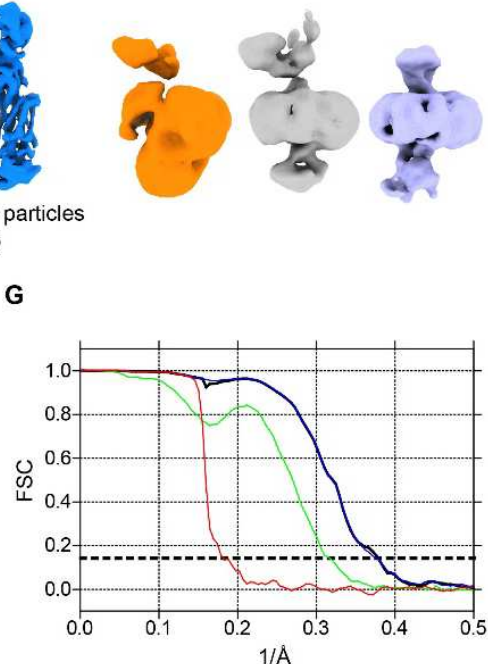

Figure S2. Cryo-EM analysis of HKA quintuple mutant

A, a representative cryo-EM image and its Fourier transform. Bar, $50 \mathrm{~nm}$. B, representative 2D-class averages. Bar, $5 \mathrm{~nm}$. C, Angular distribution plot of particles included in the final 3D reconstruction. The number of views at each angular orientation is represented by the length and color of cylinders. Red indicates more views. D, Data processing (see Materials and Methods). E, Final reconstruction map colored by local resolution as calculated by RELION3.1. F, EM density maps of indicated regions. G, FSC plot used for resolution estimations. 


\section{Table S1. Thermal stabilities of HKA mutants}

Thermal stabilities $\left(T_{\mathrm{m}}\right)$ of mutants evaluated in this study are summarized. See Fig. 2 and experimental procedures for details. Analyzed resolution of the crystal structures using indicated mutants are shown.

${ }^{1} \mathrm{~N}$-terminal deleted construct is referred to as WT. ${ }^{2}$ Tyr799Trp mutant that prefers the $\mathrm{K}^{+}$-occluded state. ${ }^{3} \mathrm{PDB}$ ID: $5 y \mathrm{ylv} .{ }^{4} \mathrm{Pdb}$ ID: $6 \mathrm{jxh} .{ }^{5} \mathrm{No}$ crystals obtained. ${ }^{6} \mathrm{Crystal}$ diffracted to around $20 \AA$.

$\begin{array}{cccc}\begin{array}{c}\text { Construct, } \\ \text { conformation }\end{array} & \text { mutant } & T_{\mathrm{m}},{ }^{\circ} \mathrm{C} & \text { resolution, } \AA \\ & \mathrm{WT} & 46.2 & 2.8^{3} \\ \mathrm{WT}^{1}, & \mathrm{KS} & 42.8 & 3.1 \\ (\mathrm{SCH}) \mathrm{E} 2 \mathrm{BeF} & \mathrm{KS} / \mathrm{ED} & 40.1 & 4.5 \\ & \mathrm{KS} / \mathrm{KD} / \mathrm{YN} & 48.2 & 3.2 \\ & \mathrm{KS} / \mathrm{ED} / \mathrm{YN} / \mathrm{EV} & 46.7 & 3.1 \\ & \mathrm{WT} & 45.5 & 2.5^{4} \\ & \mathrm{KS} & 41.0 & -5 \\ \mathrm{Y}^{2} & \mathrm{KS} / \mathrm{ED} & 41.0 & - \\ \left(\mathrm{K}^{+}\right) \mathrm{E} 2-\mathrm{AlF} & \mathrm{KS} / \mathrm{KD} / \mathrm{YN} & 37.6 & - \\ & \mathrm{KS} / \mathrm{ED} / \mathrm{YN} / \mathrm{EV} & 42.8 & \sim 20^{6}\end{array}$


Table S2. Normalized ATPase activities of mutant enzymes

The maximum values of $\mathrm{K}^{+}$-dependent ATPase activities in the membrane fractions prepared from cells expressing indicated mutants are shown $\left(V_{\max }, \mathrm{mmol} / \mathrm{mg} / \mathrm{h}\right)$. The expression levels in the membrane fractions were determined by monitoring the fluorescence of N-terminus GFP-tag separated by FSEC (Peak/mg, in a.u.). Normalized ATPase activities were then obtained as their activity per detected fluorescence, and compared to the WT (as 100\%). Apparent $\mathrm{K}^{+}$-affinities for the ATPase activity are also indicated $\left(K_{0.5, \mathrm{~K}^{+}}\right)$.

$\begin{array}{ccccc}\text { construct } & \text { Peak/mg } & \begin{array}{c}V_{\max }, \\ \mathrm{mmol} / \mathrm{mg} / \mathrm{h}\end{array} & \begin{array}{c}K_{0.5, \mathrm{~K}+}, \mathrm{mM} \\ \mathrm{WT}\end{array} & \begin{array}{c}\text { Normalized } V_{\max }, \% \\ \text { of } \mathrm{WT}\end{array} \\ \mathrm{KS} & 6200 & 3.5 & 1.25 & 100 \\ \mathrm{KS} / \mathrm{ED} & 4800 & 0.26 & 0.26 & 10.6 \\ \mathrm{KS} / \mathrm{ED} / \mathrm{YN} & 5200 & 0.20 & 50.0 & 5.9 \\ \mathrm{KS} / \mathrm{ED} / \mathrm{YN} / \mathrm{EV} & 9500 & 0.51 & 7.62 & 12.6 \\ \mathrm{KS} / \mathrm{ED} / \mathrm{YN} / \mathrm{EV} / \mathrm{YW} & 10500 & 1.09 & 0.77 & 24.3\end{array}$


Table S3. Data collection and refinement statistics

${ }^{1}$ Statistics for the highest-resolution shell are shown in parentheses.

\begin{tabular}{|c|c|c|c|c|c|c|c|c|c|}
\hline & $\mathbf{K S}$ & $\begin{array}{c}\mathbf{K S} \\
\left(\mathbf{R \mathbf { b } ^ { + }}\right)\end{array}$ & KS/ED & $\begin{array}{c}\text { KS/ED } \\
\left(\mathbf{R b}^{+}\right)\end{array}$ & $\begin{array}{c}\text { KS/ED/ } \\
\text { YN }\end{array}$ & $\begin{array}{c}\mathbf{K S} / \mathbf{E D} / \mathbf{Y} \\
\mathbf{N}\left(\mathbf{R b}^{+}\right)\end{array}$ & $\begin{array}{c}\text { KS/ED/Y } \\
\mathbf{N} / \mathbf{E V}\end{array}$ & $\begin{array}{c}\mathbf{K S} / \mathbf{E D} / \mathbf{Y} \\
\mathbf{N} / \mathbf{E V} \\
\left(\mathbf{R b ^ { + }}\right)\end{array}$ & $\begin{array}{c}\text { Wildtype } \\
\left(\mathbf{R b}^{+}\right)\end{array}$ \\
\hline PDB & 7EFL & - & - & - & 7EFM & - & $7 \mathrm{EFN}$ & - & 5YLV \\
\hline \multicolumn{10}{|l|}{$\begin{array}{l}\text { Data } \\
\text { collection }\end{array}$} \\
\hline $\begin{array}{l}\text { Wave } \\
\text { length }(\AA))\end{array}$ & 1.00 & 0.814 & 1.00 & 0.814 & 1.00 & 0.814 & 1.00 & 0.814 & 0.814 \\
\hline $\begin{array}{l}\text { Resolution } \\
\text { (§) }\end{array}$ & $\begin{array}{c}46-3.4 \\
(3.5- \\
3.4)^{1}\end{array}$ & $\begin{array}{c}48-3.7 \\
(3.8-3.7)\end{array}$ & $\begin{array}{c}48-4.5 \\
(4.7-4.5)\end{array}$ & $\begin{array}{c}48-4.5 \\
(4.7-4.5)\end{array}$ & $\begin{array}{c}48-3.2 \\
(3.3-3.2)\end{array}$ & $\begin{array}{c}48-3.2 \\
(3.3-3.2)\end{array}$ & $\begin{array}{c}46-3.2 \\
(3.3-3.2)\end{array}$ & $\begin{array}{c}48-4.0 \\
(4.1-4.0)\end{array}$ & $\begin{array}{c}48-3.4 \\
(3.5-3.4)\end{array}$ \\
\hline $\begin{array}{l}\text { Space } \\
\text { group }\end{array}$ & $P 3_{1} 21$ & $P 3_{1} 21$ & $P 3_{1} 21$ & $P 3_{1} 21$ & $P 3_{1} 21$ & $P 3_{1} 21$ & $P 3_{1} 21$ & $P 3_{1} 21$ & $P 3_{1} 21$ \\
\hline \multicolumn{10}{|l|}{$\begin{array}{l}\text { Cell } \\
\text { dimension }\end{array}$} \\
\hline$a, b, c(\AA)$ & $\begin{array}{c}105.0,1 \\
05.0,36 \\
9.9\end{array}$ & $\begin{array}{l}104.5 \\
104.5 \\
367.2\end{array}$ & $\begin{array}{l}103.9 \\
103.9 \\
368.3\end{array}$ & $\begin{array}{l}103.9, \\
103.9, \\
368.3\end{array}$ & $\begin{array}{l}104.7 \\
104.7 \\
368.0\end{array}$ & $\begin{array}{l}104.7 \\
104.7 \\
368.0\end{array}$ & $\begin{array}{l}105.9, \\
105.9, \\
372.0\end{array}$ & $\begin{array}{l}105.3, \\
105.3, \\
370.9\end{array}$ & $\begin{array}{l}106.1, \\
106.1, \\
371.6\end{array}$ \\
\hline$\alpha, \beta, \gamma\left({ }^{\circ}\right)$ & $\begin{array}{c}90,90 \\
120\end{array}$ & $\begin{array}{c}90,90 \\
120\end{array}$ & $\begin{array}{c}90,90 \\
120\end{array}$ & $\begin{array}{c}90,90 \\
120\end{array}$ & $\begin{array}{c}90,90 \\
120\end{array}$ & $\begin{array}{c}90,90 \\
120\end{array}$ & $\begin{array}{c}90,90 \\
120\end{array}$ & $\begin{array}{c}90,90 \\
120\end{array}$ & $\begin{array}{c}90,90 \\
120\end{array}$ \\
\hline $\boldsymbol{R}_{\text {merge }}$ & $\begin{array}{l}0.165 \\
(2.48)\end{array}$ & $\begin{array}{l}0.032 \\
(0.95)\end{array}$ & $\begin{array}{l}0.017 \\
(0.42)\end{array}$ & $\begin{array}{l}0.018 \\
(1.35)\end{array}$ & $\begin{array}{c}0.11 \\
(2.58)\end{array}$ & $\begin{array}{l}0.033 \\
(1.35)\end{array}$ & $\begin{array}{l}0.033 \\
(2.60)\end{array}$ & $\begin{array}{l}0.027 \\
(0.51)\end{array}$ & $\begin{array}{l}0.034 \\
(0.44)\end{array}$ \\
\hline$R_{\text {pim }}$ & $\begin{array}{c}0.039 \\
(0.548)\end{array}$ & $\begin{array}{l}0.032 \\
(0.95)\end{array}$ & $\begin{array}{l}0.017 \\
(0.42)\end{array}$ & $\begin{array}{l}0.018 \\
(1.35)\end{array}$ & $\begin{array}{l}0.026 \\
(0.57)\end{array}$ & $\begin{array}{l}0.033 \\
(1.35)\end{array}$ & $\begin{array}{l}0.033 \\
(2.60)\end{array}$ & $\begin{array}{l}0.027 \\
(0.51)\end{array}$ & $\begin{array}{l}0.034 \\
(0.44)\end{array}$ \\
\hline$I / \mathbf{s} I$ & $\begin{array}{c}12.4 \\
(1.35)\end{array}$ & $\begin{array}{c}10.8 \\
(0.74)\end{array}$ & $\begin{array}{c}11.4 \\
(1.91)\end{array}$ & $\begin{array}{c}9.13 \\
(0.71)\end{array}$ & $\begin{array}{l}16.8 \\
(1.6)\end{array}$ & $\begin{array}{l}11.0 \\
(0.54)\end{array}$ & $\begin{array}{c}9.15 \\
(0.28)\end{array}$ & $\begin{array}{c}8.99 \\
(1.07)\end{array}$ & $\begin{array}{c}15.7 \\
(1.44)\end{array}$ \\
\hline$C / C_{1 / 2}$ & $\begin{array}{c}0.99 \\
(0.79)\end{array}$ & $1(0.40)$ & $1(0.95)$ & $1(0.62)$ & $\begin{array}{c}0.99 \\
(0.85)\end{array}$ & $1(0.32)$ & $1(0.16)$ & $1(0.90)$ & $1(0.72)$ \\
\hline $\begin{array}{l}\text { Completen } \\
\text { ess }(\%)\end{array}$ & $\begin{array}{l}99.8 \\
(99.8)\end{array}$ & $\begin{array}{c}85.7 \\
(13.1)\end{array}$ & $\begin{array}{c}98.3 \\
(98.0)\end{array}$ & $\begin{array}{c}98.3 \\
(98.0)\end{array}$ & $\begin{array}{c}94.8 \\
(56.6)\end{array}$ & $\begin{array}{c}94.8 \\
(56.6)\end{array}$ & $\begin{array}{c}81.7 \\
(25.2)\end{array}$ & $\begin{array}{c}98.6 \\
(96.8)\end{array}$ & $\begin{array}{c}99.2 \\
(97.5)\end{array}$ \\
\hline $\begin{array}{l}\text { Redundanc } \\
\mathbf{y}\end{array}$ & $\begin{array}{c}20.0 \\
(21.1)\end{array}$ & $2.0(2.0)$ & $2.0(2.0)$ & $2.0(2.0)$ & $\begin{array}{l}20.1 \\
(21.4)\end{array}$ & $2.0(2.0)$ & $2.0(2.0)$ & $2.0(2.0)$ & $2.0(2.0)$ \\
\hline
\end{tabular}

\section{Refinement}

\begin{tabular}{|c|c|c|c|}
\hline $\begin{array}{l}\text { No. of } \\
\text { reflections }\end{array}$ & $\begin{array}{l}33564 \\
(3274)\end{array}$ & $\begin{array}{l}39699 \\
(2203)\end{array}$ & $\begin{array}{l}41073 \\
(1017)\end{array}$ \\
\hline$R_{\mathrm{w}} / \boldsymbol{R}_{\mathrm{f}}(\%)$ & $\begin{array}{c}23.0 / 28 \\
.9 \\
(32.2 / 3 \\
5.0)\end{array}$ & $\begin{array}{c}22.8 / 29 \\
1 \\
(31.4 / 37 \\
.7)\end{array}$ & $\begin{array}{c}27.1 / 30.7 \\
(36.8 / 38.9 \\
)\end{array}$ \\
\hline
\end{tabular}




\begin{tabular}{lccc}
\hline $\begin{array}{l}\text { Wilson } \boldsymbol{B} \text { - } \\
\text { factor }\end{array}$ & 94.6 & 82.1 & 58.03 \\
\hline $\begin{array}{l}\text { No. of } \\
\text { atoms }\end{array}$ & 9756 & 9816 & 9844 \\
\hline Protein & 9697 & 9747 & 9733 \\
\hline Ligands & 59 & 69 & 111 \\
\hline $\begin{array}{l}\text { Average } \boldsymbol{B} \text { - } \\
\text { factor }\end{array}$ & 101 & 83.5 & 60.1 \\
\hline $\begin{array}{l}\text { Protein } \\
\left(\AA^{2}\right)\end{array}$ & 101.1 & 83.2 & 60.0 \\
\hline $\begin{array}{l}\text { Ligands } \\
\left(\AA^{2}\right)\end{array}$ & 97.9 & 113.9 & 68.2 \\
\hline $\begin{array}{l}\text { R.m.s. } \\
\text { deviations }\end{array}$ & 1.34 & 1.33 & 0.88 \\
\hline $\begin{array}{l}\text { Bond } \\
\text { length }(\AA)\end{array}$ & 0.012 & 0.01 & \\
\hline $\begin{array}{l}\text { Bond } \\
\text { angles }\left({ }^{\circ}\right)\end{array}$ & & & \\
\hline
\end{tabular}


Table S4. Cryo-EM data collection, processing, refinement and validations Data collection and processing

\begin{tabular}{lc}
\hline EMBD-ID & EMD-31294 \\
\hline PDB-ID & 105,000 \\
\hline Magnification & 300 \\
\hline Voltage (kV) & 48 \\
\hline Electron exposure (e $\left./ \AA^{2}\right)$ & $0.8-1.8$ \\
\hline Defocus range (mm) & 0.83 \\
\hline Pixel size $(\AA)$ & $C 1$ \\
\hline Symmetry & 794,705 \\
\hline Initial particle images (no.) & 72,308 \\
\hline Final particle images (no.) & 2.6 \\
\hline Map resolution ( $\AA$ ) & 0.143 \\
\hline FSC threshold & \\
\hline
\end{tabular}

\begin{tabular}{lc}
\hline Refinement & \\
\hline Model composition & 10029 \\
Non-hydrogen atoms & 1249 \\
Protein residues & 1 Water, $3 \mathrm{~K}^{+}, 1 \mathrm{Mg}^{2+}, 1 \mathrm{AlF}_{4}^{-}, 2 \mathrm{PCW}, 1 \mathrm{CLR}$ \\
Ligands & 21.99 \\
\hline B-factors & 32.58 \\
Protein & 33.53 \\
Ligand & \\
Water & 0.005 \\
\hline R.m.s. deviations & 0.771 \\
Bond length $(\AA)$ & \\
Bond angles $\left({ }^{\circ}\right)$ & 2.16 \\
\hline Validation & \\
MolProbity score & \\
Clash score & \\
Poor rotamers $(\%)$ & \\
& \\
\hline
\end{tabular}


Ramachandran plot

Favored (\%)

97.3

Allowed (\%)

2.73

Outlaier (\%)

0.00 
Table S5. Coordination geometry and partial valence in the $\mathrm{K}^{+}$-binding site of HKA and NKA Partial valence was calculated for $\mathrm{K}^{+}$in each corresponding structures. Only oxygen atoms within $4 \AA$ of $\mathrm{K}^{+}$ were included for the valence calculation.

\begin{tabular}{|c|c|c|c|c|c|c|c|}
\hline PDB & \multicolumn{4}{|c|}{ 7ET1 (present study) } & \multicolumn{3}{|c|}{ 2zxe (ref. 18) } \\
\hline protein & \multicolumn{4}{|c|}{ HKA quintuple mutant } & \multicolumn{3}{|c|}{ NKA wild type } \\
\hline state & \multicolumn{4}{|l|}{$\left(\mathrm{K}^{+}\right)_{2} \mathrm{E} 2-\mathrm{AlF}$} & \multicolumn{3}{|c|}{$\left(\mathrm{K}^{+}\right)_{2} \mathrm{E} 2-\mathrm{MgF}$} \\
\hline \multirow[t]{10}{*}{ site } & Amino acids & Atom & Distance & Valence & Distance & Valence & \\
\hline & Thr788 & $\mathrm{O}$ & 2.90 & 0.11 & 2.73 & 0.19 & (Thr779 O) \\
\hline & Lys791Ser & $\mathrm{O} \gamma$ & 2.70 & 0.21 & 2.79 & 0.16 & $(\mathrm{Ser} 782 \mathrm{O} \gamma)$ \\
\hline & Asn792 & $\mathrm{O} \delta 1$ & 2.79 & 0.16 & 2.87 & 0.12 & $(\operatorname{Asn} 783 \mathrm{O} \delta)$ \\
\hline & Glu795 & $\mathrm{O} \varepsilon 1$ & 3.74 & 0.01 & 3.88 & 0.01 & (Glu786 Oع1) \\
\hline & & $\mathrm{O} \varepsilon 2$ & 3.92 & 0.01 & & & \\
\hline & Glu820Asp & $\mathrm{O} \delta 1$ & 2.93 & 0.10 & 3.15 & 0.05 & (Asp811 O 81$)$ \\
\hline & & & & & 2.67 & 0.23 & 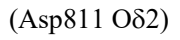 \\
\hline & Asp824 & $\mathrm{O} \delta 1$ & 3.13 & 0.06 & & & \\
\hline & & & & & 2.6 & 0.30 & $\left(\mathrm{H}_{2} \mathrm{O} 001\right)$ \\
\hline \multirow[t]{5}{*}{ Total valence } & & & & 0.65 & & 1.06 & \\
\hline & Val338 & $\mathrm{O}$ & 3.09 & 0.06 & 3.00 & 0.08 & (Val329 O) \\
\hline & Ala339 & $\mathrm{O}$ & 2.98 & 0.09 & 3.04 & 0.07 & (Ala330 O) \\
\hline & Val341 & $\mathrm{O}$ & 2.73 & 0.19 & 2.76 & 0.17 & (Val332 O) \\
\hline & Glu343 & $\mathrm{O} \varepsilon 1$ & 3.38 & 0.03 & 3.35 & 0.03 & (Glu334 Os1) \\
\hline \multirow[t]{5}{*}{ II } & & $\mathrm{O} \varepsilon 2$ & & & & & \\
\hline & Asn792 & $\mathrm{O} \delta 1$ & 3.21 & 0.04 & 3.07 & 0.07 & (Asn783 O 81$)$ \\
\hline & Glu795 & $\mathrm{O} \varepsilon 1$ & 2.94 & 0.10 & 2.91 & 0.11 & (Glu786 Oe1) \\
\hline & Glu820Asp & $\mathrm{O} \delta 1$ & 2.82 & 0.14 & 3.77 & 0.01 & (Asp811 O 81$)$ \\
\hline & & $\mathrm{O} \delta 2$ & 3.40 & 0.03 & 2.94 & 0.1 & (Asp811 O 82$)$ \\
\hline Total valence & & & & 0.68 & & 0.64 & \\
\hline
\end{tabular}




\section{Supplementary Files}

This is a list of supplementary files associated with this preprint. Click to download.

- nrreportingsummaryKazuhiroAbe.pdf 